\title{
The Effects of Real Earnings Management on the Firm, \\ Its Competitors and Subsequent Reporting Periods
}

\author{
Craig J Chapman \\ Kellogg School of Management \\ Northwestern University \\ 2001 Sheridan Road \\ Jacobs Center \#6227 \\ Evanston IL 60208 \\ c-chapman@kellogg.northwestern.edu
}

February 16, 2009

\begin{abstract}
:
Prior research hypothesizes that managers use a variety of 'real actions' to manage reported earnings to meet or beat certain key benchmarks. Combining two years of new supermarket scanner data for a commodity consumer product with firm-level financial data, I find evidence consistent with the hypothesis of price discounting around the fiscal quarter-end. Firms that just beat prior year quarterly Earnings per Share or Analyst Consensus Earnings Forecasts reduce prices in the final month of the fiscal quarter to do so even when controlling for the effects of a competing hypothesis that firms adjust prices when inventory levels are unusually high.
\end{abstract}

Also examined are the effects of earnings management related price reductions on subsequent reporting periods and on competitor pricing behavior. I find that price reductions associated with a single earnings

I appreciate the helpful comments of my dissertation committee: Paul M. Healy (Chair), V.G. Narayanan and Thomas J. Steenburgh. I should also like to thank Krishna Palepu, Eddie Riedl, Brian Rountree, J.B. Steenkamp and Lloyd Tanlu as well as seminar participants at the 2008 American Accounting Association Annual Meeting, Columbia University, Dartmouth College, Harvard Business School, New York University, Northwestern University, Stanford University, University of North Carolina and Yale University for their helpful comments and also representatives of the anonymous supermarket chain who provided the data for this research. 
management target are persistent over multiple reporting periods and that competitors also reduce prices when a firm has greater incentives to accelerate earnings.

These findings suggest the effects of Real Earnings Management on subsequent reporting periods and competitor behavior are greater than previously thought and make contribute to both the marketing and accounting literature in the following ways:

- analyzing the effect of price discounts on earnings as opposed to the effect on sales volumes and revenues;

- demonstrating evidence that firms manufacturing durable goods reduce prices (an increase in promotional activities) when incentives to boost earnings are stronger; ${ }^{1}$

- offering direct evidence of the actions taken to manage earnings, as opposed to the prior research which uses Abnormal Cash Flow from Operations as a proxy for earnings management actions ${ }^{2}$;

- providing evidence that firms change pricing behavior in response to competitor earnings management incentives;

- showing that price reductions associated with earnings management become persistent and can be repeated as much as twelve months later.

\footnotetext{
${ }^{1}$ This is in contrast to prior research which suggests that firms reduce discretionary expenditures to boost reported earnings.

${ }^{2}$ See Gunny (2005), Roychowdhury (2006) and Cohen, Dey and Lys (2008).
} 


\section{Introduction}

This paper examines the use of price discounts at the fiscal quarter-end to manage reported earnings, as well as the effects of such price discounts on competitors' pricing behavior and subsequent reporting periods.

Prior research indicates that in addition to using financial reporting judgment, managers use a variety of 'real actions' to manage reported earnings to meet or beat certain key benchmarks. ${ }^{3}$ For durable goods, price reductions prior to the fiscal quarter-end are legal and can be used to boost sales volumes and earnings temporarily. This makes them ideal as earnings management tools. Observed price changes are examples of Real Earnings Management through Operating ${ }^{4}$ as opposed to Investing ${ }^{5}$ or Financing ${ }^{6}$ activities which have been studied elsewhere.

According to SEC complaints and allegations, many companies artificially inflate their reported revenues by deliberately sending retailers, along the distribution channel, more products than they are able to sell (a process referred to as "channel stuffing"). In contrast, firms which inflate their reported revenues by selling end consumers more than they currently require are rarely scrutinized. In order to encourage customers to accept shipments of product, firms often offer discounts or extended credit terms.

Provided relevant revenue recognition criterion are satisfied, offering such price discounts to boost current period earnings is not illegal and appears to be a common practice. For example, Chrysler, Ford and General Motors all reported significant sales growth in the summer of 2005 associated with offers of

\footnotetext{
${ }^{3}$ See Schipper (1989), Healy and Wahlen (1999), Graham, Harvey and Rajgopal (2005), Gunny (2005), Roychowdhury (2006) or Chapman and Steenburgh (2008) for examples. ${ }^{4}$ See also Mizik and Jacobsen (2007) and Chapman and Steenburgh (2008) for a discussion of the role of marketing expenditure in this context.

${ }^{5}$ See Baber et al (1991), Dechow and Sloan (1991), Bushee (1998), Bens, Nagar and Wong (2002) and Cheng (2004) for discussions of the role of changing R\&D expenditure or Bartov (1993) and Herrmann, Inoue and Thomas (2003) for discussions on the use of asset sales in various earnings management contexts.

${ }^{6}$ See McNichols and Wilson (1988) on the use of opportunistic provisioning.
} 
'Employee Discounts for All. ${ }^{, 7}$ In this case, price reductions close to the end of the fiscal period were boosting sales in one reporting period but may have also affected future sales levels adversely. Evidence of a subsequent sales decline for the auto manufacturers was reported by the New York Times: "General Motors, Ford and Chrysler held their lowest shares of the American market ever last month. Sales fell in the wake of high gasoline prices, fears about the economy and consumer resistance to buying cars without the big discounts the companies offered this summer."

However, the effectiveness of promotions is directly linked to the promotional activities of competitors as evidenced by a recent statement made by Douglas R. Conant, President and Chief Executive Officer of Campbell Soup Company during their quarterly earnings conference call "We then managed our marketing plans to manage our [earning $]^{9}$....to ensure that we were supporting the business but also delivering our earnings and at the same time competition was more competitively successful than they had been in prior years." (Campbell Soup Company, 2008).

To test whether price reductions are used in this manner, I examine firms that just beat prior year quarterly Earnings per Share (“EPS Target”) or Analyst Consensus Earnings Forecasts (“ACEF Target”). These firms are expected to have had incentives to boost earnings in order to reach these targets.

If customers stockpile product that is discounted at the end of a quarter, ${ }^{10}$ purchase demand is likely to decline in the following quarter. I investigate this relationship and whether it leads to an increased likelihood of price discounts in subsequent periods as the firm seeks to support dwindling sales.

Finally, given the association of brand switching with price reductions ${ }^{11}$ and the substitute nature of the product studied, price reductions in one firm are also likely to affect the pricing behavior of competitors

\footnotetext{
${ }^{7}$ White (2005), Eyes on the Road: the Employee Discount Game.

${ }^{8}$ Maynard and Peters (2005), Big Drop in October for Detroit.

${ }^{9}$ The word "earning" can be clearly heard at time 33:40 in the audio version of the conference call but has been redacted from the call transcript available at http://seekingalpha.com/article/77913-campbell-soup-f3q08-qtr-end-427-08-earnings-call-transcript?page $=-1$

${ }^{10}$ Gupta (1988) proposes that sales increases associated with price promotions are caused, in part, by customer stockpiling.
} 
seeking to protect their own market position. Therefore, I examine the interaction between a firm's earnings management incentives and the pricing behavior of its competitors.

This paper uses a new dataset containing two years of supermarket scanner data for a commodity consumer product (soup). The granularity of the scanner data allows direct observation of the price discounting behavior which previously has only been studied indirectly. ${ }^{12}$ Soup was selected as the product category for four distinct characteristics:

- $\quad$ its non-perishable (durable) nature

- $\quad$ its frequency of purchase

- its price elasticity of demand and

- $\quad$ ease of stockpiling by the end consumer

These characteristics suggest it might be a good candidate for use in earnings management activities.

The findings show that firms who just beat either their EPS or ACEF Targets reduce prices by an average of $10-15 \%$ in the final month of the fiscal quarter, even after controlling for abnormal inventory levels. Further, the earnings management related discounting is persistent; firms that reduce prices to meet EPS Targets at the end of one fiscal quarter reduce their prices again twelve months later by an estimated $7 \%$. Such subsequent price reductions are above and beyond the levels predicted based upon contemporaneous earnings management incentives. Consistent with the prediction about competitor response, earnings management incentives at one firm are related to competitor price discounting. Assuming the market share of firms that are expected to be managing their earnings upwards is $20 \%$, these discounts are estimated to be $25 \%$ and $5 \%$ if the firm just beats its EPS Target and ACEF Target, respectively.

\footnotetext{
${ }^{11}$ See Gupta (1988).

${ }^{12}$ In contrast to the direct evidence presented here, prior research by Gunny (2005) and Roychowdhury (2006) uses a model from Dechow, Kothari and Watts (1998) to estimate the normal level of Cash Flow from Operations. They then propose that abnormally high production costs are indicative of overproduction to decrease Cost of Goods Sold or sales manipulation.
} 
These results are consistent with firms discounting prices to achieve earnings benchmarks and show these actions span multiple reporting periods and also affect competitor pricing behavior.

The remainder of this paper is organized as follows: Section 2 provides background, describes prior research and develops testable hypotheses about the timing and effects of price discounting behavior. Section 3 describes the sample selection procedure and research methodology. Section 4 presents empirical results and section 5 contains concluding remarks.

\section{Hypothesis Development}

\subsection{Short-Term Earnings Increase from Price Discounts}

The interplay between the use of accounting discretion and real actions to manage earnings has been of interest to academics for several years. Bruns and Merchant (1990) find that managers consider the management of short-term earnings by accounting methods to be significantly less acceptable than accomplishing the same ends by changing or manipulating operating decisions or procedures. Similarly, Ewert and Wagenhofer (2005) show that in a rational expectations model, managers increase costly real earnings management in response to tighter accounting standards.

Graham, Harvey and Rajgopal (2005) surveyed managers and concluded that they are more likely to make real economic decisions to manage earnings than to take accounting actions. $78 \%$ of managers surveyed admit to taking actions which sacrifice long-term value to smooth earnings and choose real actions over accounting actions to meet earnings benchmarks.

Gunny (2005) summarizes four activities which, according to prior research, firms use to manage earnings: 
- cutting Research and Development ("R\&D") to increase income; ${ }^{13}$

- changing Sales, General and Administration ("SG\&A") expenditure to increase income; ${ }^{14}$

- timing income (and loss) recognition from the disposal of long-lived assets and investments ${ }^{15}$

- discounting prices to boost sales in the current period and/or overproducing to decrease Cost of Goods Sold (“COGS”). ${ }^{16}$

Her evidence suggests that all four types of real earnings management negatively impact subsequent operating performance.

Prior studies on real earnings management, including Gunny (2005), Roychowdhury (2006) and Cohen, Dey and Lys (2008), estimate abnormal cash flow from operations and abnormal production costs to infer earnings management. However, they cannot explicitly test whether their results are caused by price discounting or overproduction. Similarly, Oyer (1998) infers price changes from cost data as opposed to directly observing prices.

The data in this study use observations of actual price changes at the product level. This makes it possible to extend the work presented in Chapman and Steenburgh (2008) and test whether price discounts are related to multiple earnings management incentives of the firm and its competitors. I am unaware of any other papers which use recent data at this level of granularity to provide evidence of price discounting around the end of the fiscal period.

Within the field of marketing there has been considerable research on customer response to price discounting. Gupta (1988) decomposes the sales 'bump' during the promotional period into three

\footnotetext{
${ }^{13}$ See Baber et al (1991), Dechow and Sloan (1991), Bushee (1998), Bens, Nagar and Wong (2002) and Cheng (2004) for further discussions of the role of changing R\&D expenditure in various earnings management contexts. ${ }^{14}$ See Mizik and Jacobsen (2007) and Chapman and Steenburgh (2008) for further discussion of the role of marketing expenditure in this context.

${ }^{15}$ See Bartov (1993) and Herrmann, Inoue and Thomas (2003) for further discussions on the use of asset sales or McNichols and Wilson (1988) on the use of opportunistic provisioning in this context.

${ }^{16}$ See Thomas and Zhang (2002) on the use of overproduction and Roychowdhury (2006) or Chapman and Steenburgh (2008) for further discussion on the role of price discounting.
} 
components: increased overall consumption (market growth), purchase time acceleration (stockpiling) and brand switching. Macé and Neslin (2004) present evidence that temporary price reductions can be used to increase revenues during the promotion period. However, they also show a dip in sales volume both before and after the promotion as consumers are able to time purchases.

Temporary price reductions increase earnings through the end of the price promotion if the contribution from increased sales during the promotion is sufficient to offset foregone contribution from lost sales prior to the promotion as well as reduced revenues from the lower priced sales during the promotion. Ceteris paribus, firms with lower marginal costs (higher margins) benefit more than those with high marginal costs from this type of behavior. Further, if there is a large post-promotion dip in sales due to consumer stockpiling, a temporary price reduction can actually decrease earnings over the entire period. ${ }^{17}$

There has also been considerable operations literature considering seasonality demand patterns and socalled "Hockey Stick" demand spikes (See Bradley and Arntzen (1999) and their relation to planning of production, capacity and inventory. However, although mentioning that such patterns may be selfinduced and driven by corporate business practices, these papers do not consider the causes of such behavior or any linkage to financial performance.

When considering which product category to study, I draw on prior research by Narasimham, Neslin and Sen (1996) and Hanssens, Pauwels, and Siddarth (2002) who find that soup, a non-perishable (durable) product, is easily stockpiled and purchased in greater quantities when offered at a discount. Together with its frequency of purchase, these characteristics make it a good candidate to study in relation to potential earnings management activities.

\footnotetext{
${ }^{17}$ The existence of a post-promotion sales dip is one possible explanation for the financial underperformance observed for firms following periods of earnings management, documented in papers by Teoh, Welch and Wong (1998) and Gunny (2005).
} 
Hypothesis $\mathrm{Hl}$ proposes that the relationship between customer stockpiling, limited brand switching and the price elasticity of demand for soup is such that a temporary price reduction leads to an increase in earnings prior to the end of the price promotion, but reduces total earnings over the entire period (before, during and after the promotion).

Hypothesis H1 - Increases in sales volumes, associated with a short-term price reduction, boost shortterm earnings but reduce long-term earnings.

As discussed by Arya, Glover and Sunder (1998), earnings management behavior of the type studied here, which appears costly to the firm, may exist in equilibrium for a number of reasons. First, it may not be cost-effective for participants to prevent real earnings management. Second, it may not be cost effective for some market participants to fully understand this behavior, enabling firms to access debt or equity capital at lower prices. Even if these conditions do not hold, managers may engage in real earnings management if they believe there is a possibility that some benefit will be gained.

\subsection{Price Discounting and Period-End Incentives}

A firm (or manager) facing incentives to accelerate earnings can reduce prices in one period to boost short-term earnings at the expense of long-term earnings. This behavior can give rise to earnings patterns observed by Burgstahler and Dichev (1997). ${ }^{18}$ It is also consistent with Fudenberg and Tirole (1995) and Oyer (1998) who hypothesize firms reduce prices towards the end of the period due to dividend smoothing and manager incentive effects. ${ }^{19}$

Degeorge, Patel and Zeckhauser (1999) and Graham, Harvey and Rajgopal (2005) each propose three earnings benchmarks which managers cite as being important. These relate to meeting or beating:

\footnotetext{
${ }^{18}$ Durtschi and Easton (2005) suggest that the shapes of the frequency distributions of earnings metrics at zero cannot be used as ipso facto evidence of earnings management and are likely due to the combined effects of deflation, sample selection, and differences in the characteristics of observations to the left of zero from those to the right.

${ }^{19}$ In contrast, Healy (1985) and Goel and Thakor (2003) identify several situations where managers have incentive to reduce earnings and would therefore be motivated to increase prices.
} 
- EPS from the same quarter in the previous year ("EPS Target");

- Analyst Consensus Earnings Forecasts (“ACEF Target”);

- Zero quarterly profit. ${ }^{20}$

These papers all suggest that the marginal benefit of earnings management increases sharply as earnings are managed upwards across these benchmarks giving rise to the following Hypothesis $H 2{ }^{21}$

Hypothesis H2 - Firms reduce prices at their fiscal quarter-end to meet or beat their EPS or ACEF Target.

\subsection{Inventory Management as an Alternative Explanation}

Although temporary price reductions can be used to increase earnings prior to the end of the price promotion, firms with unusually high inventory levels may also use pricing decisions to bring inventory back to a normal range. $^{22}$ Blattberg, Eppen and Lieberman (1981) discuss this argument further and propose that retailers offer 'deals' because they have higher inventory holding costs than some consumers. Using data from 1958-1966, they show evidence of consumer stockpiling across multiple product categories. However, they do not consider the possibility that abnormal inventory levels induce the price promotion behavior. Hypothesis $H 3$ is designed to examine this question:

Hypothesis H3 - Firms reduce prices when inventory levels are unusually high.

\footnotetext{
${ }^{20}$ Degeorge, Patel and Zeckhauser (1999) propose studying firms with EPS in the range 0-1 $\varnothing$ when considering earnings management incentives around the zero profit. However, the sample period used here encompasses generally positive results for most of the firms studied with no observations in this range and few in the $0-10 \varnothing$ range. I leave for future consideration the role of 'beating zero' as an earnings management incentive of this type.

${ }^{21}$ See Burgstahler and Dichev (1997) for a further discussion of the motivation to manage earnings past miscellaneous benchmarks.

${ }^{22}$ I thank Ross Watts and seminar participants at Harvard Business School for pointing out this possibility.
} 


\subsection{Competitive Response}

Prior research has considered the intra-industry contagion effects of various actions and announcements on firm valuations. ${ }^{23}$ These generally consider changes in market valuation of competitor firms around disclosures affecting a single firm. The effect on competitors' valuations is consistent with investors ascribing a higher likelihood that the competitor firms will experience similar economic outcomes to the announcing firm.

For example, when considering a sample of firms prosecuted by the Securities and Exchange Commission for fraudulent reporting ("Scandal Firms”), Karaoglu, Sandino and Beatty (2006) present evidence suggesting that competing firms manage earnings more (as measured through discretionary accruals) when their performance lags behind a Scandal Firm.

Extending this concept to real earnings management, this paper considers an alternative mechanism: that managers change their own pricing behavior in response to the real earnings management of competitors. This leads to the following hypothesis:

Hypothesis H4 - Competitor firms reduce prices when other firms within their industry are expected to discount prices to meet earnings targets.

The competitive response to price discounting has been widely studied in literature on strategic competition, price collusion and oligopoly. ${ }^{24}$ Although prior work considers the linkage between exogenous demand shocks and competitive pricing, I am unaware of any research which link price reductions associated with earnings management incentives to a competitive response.

\footnotetext{
${ }^{23}$ Docking, Hirschey and Jones (1997) find that the announcement of loan loss provisioning by one firm can lead to stock-price changes in non-announcing firms. Similarly, Gleason, Jenkins and Johnson (2008) show accounting restatements that adversely affect shareholder wealth at the restating firm also induce share price declines among non-restating firms in the same industry with the effects concentrated among revenue restatements.

${ }^{24}$ Examples include Green and Porter (1984), Bresnahan (1987), Borenstein and Shepard (1996) and Nevo (2001) and Che, Seetharaman and Sudhir (2007). Fudenberg and Tirole (2000) also consider the problem from the standpoint of poaching customers.
} 
Competitive responses to earnings management price discounts will only be observed if firms can either anticipate or respond quickly to competitor price changes. Both are plausible given knowledge about firms' fiscal year-ends and the timing of other types of promotions (aisle displays and feature advertisements) which are often scheduled months in advance. Indeed, the concept that firms monitor and act on information about their rivals is the basis for considerable literature on limits to discretionary disclosure. (Verrecchia 1983, 1990). Similarly, many large companies dedicate resources to organized competitive intelligence activities, defined as the collection and analysis of (generally public) data about one's competitors as part of formulating one's own strategic plans and decisions (Lavelle 2001). Finally, the lead time between the decision to act and a retail price change is normally several weeks but can be accelerated to a matter of days, if needed, depending on the nature of the supermarket pricing system.

\subsection{Persistence of Price Discounting Behavior}

The previous section suggests that firms may reduce prices at fiscal period end when they have an incentive to meet earnings targets. However, what happens at the end of the following year? Assume that in Period 1, the firm has an earnings target of $\$ 10$ but normal operations would result in earnings of $\$ 9$. By offering a small price discount, the firm can meet the earnings target of $\$ 10$. Even if we assume this 'borrowing' to be costless overall, it has the effect of reducing subsequent period earnings by $\$ 1$. At the end of the second period, if operations continue at the same level, the firm will generate earnings of $\$ 8$. (The $\$ 9$ from normal operations less the $\$ 1$ which was borrowed in period 1). To meet a $\$ 10$ target, the firm must now borrow $\$ 2$ from the future.

Another possible cause of repeated price discounting can be easily shown analytically. Under simple assumptions, one firm in a duopoly setting with no explicit incentive to reduce prices should do so as a competitive response, if its competitors act on their own beliefs that there is a non-zero probability that it will. If the occurrence of an earnings management incentive in one period causes competitors to believe that a price reduction might occur at the same time a year later, competitors will reduce prices at that time 
and induce the same response by the firm under consideration. Such models lead to Hypothesis $H 5$ which suggests price discounting behavior can become persistent, leading to price reductions in the twelfth month following the initial incentive to boost earnings:

Hypothesis H5 - Prices will be lower than 'normal' at the fiscal quarter-end twelve months after a firm just beat its EPS/ACEF Target.

\subsection{Importance of Soup to the Firm}

Fields, Lys and Vincent (2001) suggest that "rational managers would not engage in earnings management in the absence of expected benefits." Zang (2007) expands this concept to consider the tradeoffs managers make when choosing between real and accrual manipulation as a form of earnings management. To assess the potential size of the benefit available and tradeoff concepts, I consider whether the importance of soup and similar businesses to the firm affect the price changes observed when the firm (and its competitors) have earnings management incentives. One might predict that the larger the proportion of the firm's business represented by soup, the more the firm will use this earnings management technique. However, if the firms other businesses present no earnings management opportunity, one might observe the opposite result with firms cutting soup prices more severely in the event that an earnings lift was sought.

\section{Data and Methodology}

For this study, a significant new dataset collected between January 2005 and December 2006 was obtained from a leading US supermarket chain. The dataset contains information on all purchases made by 2,000 households randomly selected from the supermarket chain's clientele representing over 3.5 million purchase observations. The households are spread across the Northeastern United States where the chain is one of the largest food retailers. 
Prior research by Narasimham, Neslin and Sen (1996) and Hanssens, Pauwels and Siddarth (2002) find that soup, a durable product, is easily stockpiled and purchased in greater quantities when offered at a discount. Together with the frequency of purchase, this suggests that soup is a good candidate for use in earnings management activities. The analysis is therefore restricted to the 1,545 different UPC codes (product barcodes) within the soup category representing 41 different manufacturers with variation in fiscal year-ends as shown in figure 1.

For each individual UPC code, the dataset is expanded by identifying the product producer and ultimate parent company. For each of the parent companies, the information regarding the fiscal year-end, financial performance and analyst forecasts for each of the parent companies was retrieved from multiple sources including Thompson Financial, I/B/E/S, Corporate Websites, Compustat and One Source. Fiscal year-end information was obtained on 26 of the 41 manufacturers representing approximately $94 \%$ of the total purchase transactions within the soup category.

Summary statistics of my dataset which contains a total of over 3.6 million individual item purchases over the two years of observation, 55,451 of which are sales of soup products are shown in table 1 . Within this sub-sample, it is possible to identify the manufacturer for 53,637 (97.0\%), fiscal calendar for 52,138 (94.0\%), EPS data for 42,434 (76.5\%) and ACEF for 41,726 (75.2\%) observations.

To eliminate any bias which might be caused by the inclusion of multiple purchases of the same product at similar prices in the same week, the mean price observed for each UPC-week pair is used. ${ }^{25}$

The data selection criteria bias the sample slightly towards larger and less expensive brands. The mean of weekly sales, measured by $\operatorname{Ln}($ Weekly Units Sold), is 1.19 at a mean price of $\$ 1.59$ for the sample used compared to 0.81 at $\$ 1.81$ for the full sample.

\footnotetext{
${ }^{25}$ Sales volumes are consolidated to a single observation per UPC-week when used.
} 


\section{Results and Discussion}

\subsection{Price Elasticity of Demand}

To measure the effect of price discounting on sales volumes and profitability to test Hypothesis $H 1$, four variants of the following regression are estimated.

$$
\left.\operatorname{Ln}_{\left(\text {WeeklyUnitsSold }_{i t}\right)}\right) \alpha+\sum_{j=-2}^{2} \beta_{j} \operatorname{Ln}\left(\frac{\text { Price }_{i, t+j}}{\text { MaxPrice }_{i}-\text { Price }_{i, t+j}}\right)+\sum_{j=1}^{12} \gamma_{j} \text { Month }_{j}+\varepsilon_{i t}
$$

where WeeklyUnitsSold $_{i t}$ is the number of units of soup product $i$ sold in week $t .^{26}$ Price $_{i, t}$ is the mean price at which product $i$ is offered in week $t$. MaxPrice ${ }_{i}$ is the maximum average weekly price at which product $i$ is offered during the sample period. ${ }^{27}$ Scaling of the Price variables is designed to take account of different prices for products of different sizes and brands and allow for cross-sectional analysis. However, Price/MaxPrice is a variable bounded between zero and one. A logistic transformation $\operatorname{Ln}(p /(1-p))$ is therefore used where $p=$ Price/MaxPrice. ${ }^{28}$ This conversion expands the values to the real numbers. ${ }^{29}$ Month represents dummy variables for each calendar month.

There is significant calendar seasonality of demand as shown in figure 2. To control for this variation in tests of Hypothesis $H 1$, an approach consistent with prior literature ${ }^{30}$ is used which includes calendar month fixed effects.

\footnotetext{
${ }^{26}$ Scaling this variable by the Minimum Number of Units Sold in a week for product $i$ does not materially change the results.

${ }^{27}$ Use of a backward looking definition of Maxprice which defines the variable as the highest price at which the product has been offered up to time $t$ does not materially change the results.

${ }^{28}$ See Demsetz and Lehn (1985) for the use of similar transformations.

${ }^{29}$ Although the transformation of the independent variable is not essential here, I present results in this manner for consistency since I use the transformed price variable as the dependent variable in subsequent tests. In the sample, there were no cases where the price was zero and few where the Price $=$ MaxPrice. Use of an untransformed variable which includes observations where Price $=$ MaxPrice provides results consistent with those presented here. Similar results are also obtained if I exclude 55 observations representing high value outlying values of this variable which occur when Price is close to MaxPrice.

${ }^{30}$ See Oyer (1998) or Chapman and Steenburgh (2008).
} 
The error term $\varepsilon_{i t}$ contains information on competitor prices which may affect demand and also be correlated to the Price variable. Although this is partially mitigated by the use of the calendar month fixed effects, this may lead to correlated omitted variable bias. Model extensions including additional variables to control for average market price (results not reported) are consistent with limited brand switching behavior but do not materially affect the primary results of interest.

The four different estimations consider prices either one or two weeks before and after the week of interest ${ }^{31}$ with or without monthly fixed effects to control for demand seasonality. The time period under consideration is extended to include two weeks before and after based on results from Macé and Neslin $(2004)^{32}$ which suggest that the effects of a price change on sales volumes may be observed more than one week before and after it occurs.

Assuming a conventional downward sloping demand curve for soup, the effect of current price on current volume $\left(\beta_{0}\right)$ is predicted to be negative with price increases reducing sales volumes. However, given consumers' ability to stockpile soup, ${ }^{33}$ positive values are anticipated for the coefficients measuring the effects of recent prices on current period demand $\left(\beta_{-1}\right.$ and $\left.\sum_{j=-2}^{-1} \beta_{j}\right)$. Similarly, if consumers are able to anticipate future price changes and adjust current period purchases accordingly, ${ }^{34}$ coefficients measuring the effects of future prices on current period demand $\left(\beta_{1}\right.$ and $\left.\sum_{j=1}^{2} \beta_{j}\right)$ should also be positive.

The results of these four model estimations are shown in table 2, columns 1 through 4 . As expected, $\beta_{0}$ is negative and strongly significant suggesting that a $10 \%$ reduction in price is associated with an increase in sales volume of approximately $14 \%$.

\footnotetext{
${ }^{31}$ Extension to weeks $t-3$ and $t+3$ was also studied and provides no additional significant coefficients.

${ }^{32}$ See figure 2 of their paper.

${ }^{33}$ Narasimham, Neslin and Sen (1996) and Hanssens, Pauwels and Siddarth (2002) find that soup is easily stockpiled and purchased in greater quantities when offered at a discount.

${ }^{34}$ A process referred to a purchase deceleration in some marketing literature.
} 
This elasticity is slightly smaller in magnitude than the $-1.6 \mathrm{x}$ estimated for soup by Hanssens, Pauwels and Siddarth (2002) from data dating back to 1986-1988. However, this difference is small in size and may simply reflect changes in the importance of soup over time or differences in geography.

The coefficients on lagged prices $\left(\beta_{-1}\right.$ and $\left.\sum_{j=-2}^{-1} \beta_{j}\right)$ are positive, implying that a $10 \%$ price reduction in a given week is accompanied by a $2 \%$ reduction in sales over the following one or two weeks consistent with consumers stockpiling soup.

In contrast to the theoretical prediction, the coefficient relating to future prices $\left(\beta_{1}\right)$ is negative. ${ }^{35}$ When the model considers prices two weeks before and after the purchase (Table 2, columns 3 and 4), the overall effect of future prices on current demand $\left(\sum_{j=1}^{2} \beta_{j}\right)$ becomes insignificant. The counterintuitive negative sign on $\beta_{1}$ may be due to the following factors:

- the use of non-price promotional activities around the price change (which are unobserved here), ${ }^{36}$

- the presence of short term price increases just before price reductions; ${ }^{37}$ or

- changes in customer behavior depending on the duration of a price promotion. ${ }^{38}$

With regard to the third factor, consider a price promotion lasting two weeks which becomes less effective in the second week. This would bias upwards the estimates for the coefficients on the effect of

\footnotetext{
${ }^{35}$ Only significant at the $10 \%$ level when prices from two weeks before and after are included.

${ }^{36}$ Results of further tests (not reported) show the effects of price discounts at the fiscal year-end are greater (the post-promotion dip is deeper) than for discounts of equal size at other times of the fiscal-year. This is consistent with the possibility of increased non-price promotional activities ahead of the fiscal year-end and the earnings management hypothesis studied.

${ }^{37} \mathrm{~T}$-test results showing that prices increase just prior to the first observation of a price below the median for a particular product are not reported.

${ }^{38}$ Such complications in the estimation process are discussed at length in Van Heerde, Leeflang and Wittink (2000) and can be readily observed for comparable product categories in figure 2 of Macé and Neslin (2004).
} 
future prices on current demand $\left(\beta_{1}\right.$ and $\left.\sum_{j=1}^{2} \beta_{j}\right)$ and bias downwards the estimates for the coefficients on the effect of prior prices on current demand $\left(\beta_{-1}\right.$ and $\left.\sum_{j=-2}^{-1} \beta_{j}\right){ }^{39}$

To address this potential concern and improve model fit if customer demand levels change based upon the duration of a promotion, the model is refined by adding an additional independent variable $\operatorname{Ln}\left(\frac{\text { Price }_{i, t}}{\text { MaxPrice }_{i}-\text { Price }_{i, t}}\right) * I$ where $I$ is a dummy variable equal to one if Price $_{i, t-1}<$ Price $_{i, t}$ and zero otherwise. $^{40}$ The results are shown in table 2, column 5 , and also graphically in figures 3 and 4 for a price reduction lasting one and two weeks, respectively. These show a decline in demand during the second week of a two-week promotion, consistent with the idea that the promotion becomes less effective over time. The results on other coefficients of interest are not materially different except we now observe a clear reduction in demand both before and after the price promotion. This suggests that any concerns on mis-specification should be minimal.

Another potential concern is the possibility that firms reduce prices in response to decreases in demand. Additional tests (not reported) show that historic prices Granger cause current sales volumes but that historic sales volumes do not Granger cause current prices. ${ }^{41}$ As such, I conclude that price reductions assumed to occur in weeks 5 and 6 shown in figure 4 are not Granger caused by the reductions in sales volumes just prior to the price promotion.

Additional control variables are included in table 2, column 6, to reflect the mean price $\frac{1}{k} \sum_{i=1}^{k} \operatorname{Ln}\left(\frac{\text { Price }_{i, t}}{\text { MaxPrice }_{i}-\text { Price }_{i, t}}\right)$ observed in the market during the period from one week prior through one week following the period of observation.

\footnotetext{
${ }^{39}$ A similar concern exists and remains unresolved in the results presented by Macé and Neslin (2004).

${ }^{40}$ Use of alternative indicator variables relating to the period which precedes a price decline provides similar results.

${ }^{41}$ See Granger (1969) and Nerndt (1991).
} 
Current period competitor prices affect current period sales volumes with higher volumes associated with higher competitor prices. In contrast, competitor prices in the weeks before and after do not significantly affect current sales volumes. In spite of these relations, inclusion of competitor prices as additional control variables does not materially change the estimates of price elasticity discussed above.

\subsection{The Direct Costs and Benefits of Real Earnings Management}

The impact of a temporary price cut on profits depends on a number of factors including the product's price elasticity of demand and the firm's cost structure. To assess these, consider the following example:

Given a three week period of constant prices $\mathrm{p}$, contribution is given by $3(p-c) \cdot v$ where $c$ is the marginal cost and $v$ is the sales volume assuming all prices equal $p$. If prices are reduced to $\underline{p}$ in the middle week, the total contribution over the three weeks is given by $\left.(p-c) \cdot v\right|_{p_{t+1}=\underline{p}}+\left.(\underline{p}-c) \cdot v\right|_{p_{t}=\underline{p}}+\left.(p-c) \cdot v\right|_{p_{t-1}=\underline{\underline{p}}} \cdot{ }^{42}$

If price reductions are sufficient to boost short-term earnings through the end of a promotion, there will be a net increase in contribution before and during the price-cut evidenced by $\left.(p-c) \cdot v\right|_{p_{t+1}=\underline{p}}+\left.(\underline{p}-c) \cdot v\right|_{p_{t}=\underline{p}}>2(p-c) \cdot v$. If earnings are reduced overall, then any increased contribution before and during a price cut will be offset by the lost sales resulting from the lag effects after the promotion relating to earlier prices. Therefore: $\left.\quad(p-c) \cdot v\right|_{p_{t+1}=\underline{\underline{p}}}+\left.(\underline{p}-c) \cdot v\right|_{p_{t}=\underline{\underline{p}}}+\left.(p-c) \cdot v\right|_{p_{t-1}=\underline{\underline{p}}}<3(p-c) \cdot v$.

The regression model estimates presented in the previous section imply that a $15 \%$ price reduction lasting one (two) week(s) increases short-term earnings through the end of a promotion if marginal costs $(c)$ are

\footnotetext{
${ }^{42}$ The first component allows for anticipation of the price cut, the second component incorporates the effect of price changes when they occur and the third allows for demand changes in the period following reversion to 'normal' price.
} 
less than $34.7 \%$ (34.7\%) of regular retail price. ${ }^{43}$ Quarterly 'contribution' can be increased by up to $0.5 \%$, Gross Profit increased by $0.6 \%$ and EPS increased by $2.5 \%$ if marginal costs are $18.2 \%$ (18.7\%), gross margin is $68.1 \%(67.7 \%)$ and net margin is $16.4 \%(16.3 \%)$ of normal sale price. Greater effects on EPS may be achieved by discounting prices further depending on the operating and financial leverage of the firm. ${ }^{44}$

However, the presence of the post-promotion dip associated with the lag effects after of earlier prices $\left(\sum_{j=-2}^{-1} \beta_{j}\right)$ means that the one (two)-week $15 \%$-off promotion will be costly overall unless the marginal cost of production is below $10.3 \%(9.7 \%) .{ }^{45}$

If the marginal cost of the product is less than $10 \%$ of the regular price then it would appear profitable overall to reduce prices temporarily. However, if a firm faces such a situation, it raises the question as to why they were not previously discounting prices.

Overall, if marginal costs are between $10 \%$ and $35 \%$ of the sales price, price reductions will increase reported earnings before the end of the price promotion but will reduce total earnings over the entire period. In some cases, this cost is material. For example, a firm with a cost structure similar to ones mentioned above which boosts quarterly EPS by $2.5 \%$ using a $15 \%$ one (two)-week price reduction would reduce quarterly EPS in the following quarter by approximately 3.3\% (4.6\%) based on the depth of the post-promotion dip in sales associated with the price discount. ${ }^{46}$ This raises the possibility that firms

\footnotetext{
${ }^{43}$ Calculations of each of the values presented in this paragraph are shown in Appendix 1. The effect on EPS is highly sensitive to the net margin assumption.

${ }^{44}$ As mentioned elsewhere in this paper, manufacturer price promotions are usually structured so that the bulk of the units shipped to the supermarket at a discount must also be sold to the consumers at a discount. I thank J.B. Steenkamp for suggesting that the pass through of price reduction by the retailer may be as low as $70 \%$. In such circumstances, price reductions of $15 \%$ (50\%) can be used to temporarily boost earnings if marginal costs are below $15 \%(20 \%)$ of the retail price based upon the elasticity observed for the sample used here. Any reduction in pass through of price reductions would bias against finding results in tests of Hypotheses $\mathrm{H} 2, \mathrm{H} 4$ and $\mathrm{H} 5$.

${ }^{45}$ See Appendix 1.

${ }^{46}$ Again, more severe effects are expected following larger price reductions.
} 
may be tempted to repeat the price discount at the end of the following quarter to recover the subsequent cost which is discussed further below.

An analysis of the financial statements of sample firms shows that the contribution margin is likely within this range. Indeed, the mean Cost of Sales to Sales ratio of sample firms is approximately $60 \%$ with raw materials estimated by one of the firms in the sample to be approximately $30 \%$ of Sales. With the supermarket chain under consideration reporting gross margins of approximately $25 \%,{ }^{47}$ this implies that the average firm in the sample has marginal costs that approximate $23 \%$ of the retail price. ${ }^{48}$

Comparing this figure to the $10-35 \%$ range highlighted above demonstrates that many of the sample firms will be able to use price reductions to boost current quarter EPS which also reduce earnings in the following quarter by a greater amount consistent with Hypothesis $H 1$.

A caveat to this conclusion is that only retail prices are observed, not the manufacturer sale price. Therefore, this interpretation of results requires the supermarket chain to pass through most of the discounts/promotions from the manufacturers as opposed to selectively targeting manufacturers' performance or fiscal calendar with their own pricing activities. ${ }^{49}$ Discussion with representatives of one of the larger manufacturing companies confirmed that trade funding ${ }^{50}$ is usually structured so that the bulk of the units shipped to the supermarket at a discount must also be sold to the consumers at a discount. However, a small percentage "slip" through the system and are sold to consumers at or near full-price. If the supermarket does not pass on the price discounts from the manufacturers, this would bias my tests against finding results.

\footnotetext{
${ }^{47}$ Figure obtained from 10-K Filing of the Supermarket Chain.

${ }^{48}$ Marginal Cost $=30 \% *$ Manufacturer Sales. Manufacturer Sales $=75 \% *$ Retail Sales. Marginal Cost $=23 \%$ of Retail Sales.

${ }^{49}$ This is consistent with the approach used by Chintagunta, Kadiyali and Vilcassim $(1996,1999)$ who assume the retailer is non-strategic and charges an exogenous constant margin.

${ }^{50}$ Money given to supermarkets to temporarily reduce prices, display product in prime merchandising space, or feature product in circulars.
} 
Overall, this evidence allows the conclusion that short-term price reductions result in increased sales volumes over the sample period. These sales increases boost short-term earnings through the end of the promotion but reduce long-term earnings as a result of the drop in sales following the promotion.

Therefore, firms within the sample can use short-term price reductions to manage reported earnings but their long-term earnings are negatively affected by such behavior.

When considering how the elasticity of demand varies depending on the fiscal calendar and the timing of price changes, the dotted cumulative effect line in the left hand diagram in figure 5 shows that the cost of running a price discount at times other than the end of the fiscal quarter is negligible. However, the right hand diagram shows that price reductions at the end of the fiscal quarter are costly. This suggests that the effects discussed above are being heavily influenced by discounts at the end of the fiscal quarter.

The difference in cumulative cost of the price discount may be caused by multiple factors, including predictability of discounts by competitors leading to an increased competitive response (as discussed more below) as well as sub-optimal promotion support around quarter-end price cuts.

\subsection{Meeting and Beating Earnings Benchmarks}

Hypothesis $H 2$ proposes that firms will reduce prices at their fiscal quarter-ends to meet or beat each of the earnings benchmarks proposed in section 2.2. This is tested by studying the pricing behavior of firms just beating different earnings benchmarks and comparing them to those with earnings not in these ranges by estimating several variations to the following regression: ${ }^{51}$

\footnotetext{
${ }^{51}$ An alternative specification might consider year-on-year price change. This is a more restrictive specification but yields similar results.
} 


$$
\begin{aligned}
& \operatorname{Ln}\left(\frac{\text { Price }_{i t}}{\text { MaxPrice }_{i}-\text { Price }_{i t}}\right)=\alpha+\beta_{1} \text { JustBeatQEnd }_{i t}+\beta_{2} \text { JustMissQEnd }_{i t}+\beta_{4} \operatorname{Ln}\left(\frac{\text { Price }_{i t-52}}{\text { MaxPrice }_{i}-\text { Price }_{i t-52}}\right) \quad \text { where } \\
& +\beta_{5} \text { JustBeatQEnd }_{i t-52}+\beta_{6} \text { JustMiss QEnd }_{i t-52}+\varepsilon_{i t}
\end{aligned}
$$

Price $_{i t}$ is the mean price at which product $i$ is offered in week $t$. MaxPrice ${ }_{i}$ is the maximum average weekly price at which product $i$ is offered during the sample period. ${ }^{52}$ The scaling by MaxPrice is designed to take account of different regular prices for products of different sizes and brands and allow for cross-sectional analysis. However, Price/MaxPrice is a variable bounded between zero and one. A logistic transformation $\operatorname{Ln}(p /(1-p))$ is therefore used where $p=$ Price/MaxPrice. This conversion expands the values of the dependent variable to the real numbers. ${ }^{53}$

JustBeatQEnd $_{i t}$ is a dummy variable which equals one if the firm's earnings are 0-5\% above the relevant target (the EPS or ACEF Target ${ }^{54}$ ) and the transaction occurs in the last month of the manufacturer's fiscal quarter, and zero otherwise. JustBeatQEnd ${ }_{i t}$ is designed to identify firms and periods where there is a higher likelihood of quarter-end real earnings management. ${ }^{55}$ The coefficient $\beta_{1}$ is therefore expected to be negative.

JustMiss QEnd $_{i t}$ is a dummy variable which equals one if the firm is $0-10 \%{ }^{56}$ below the relevant earnings target (the EPS or ACEF Target) and the transaction occurs in the last month of the manufacturer's fiscal quarter, and zero otherwise. JustBeatQEnd ${ }_{i t}$ is included for comparison purposes. Therefore, I make no prediction on the sign of $\beta_{2}$.

\footnotetext{
${ }^{52}$ Use of a backward looking definition of Maxprice which defines the variable as the highest price at which the product has been offered up to time $t$ does not materially change the results.

${ }^{53}$ In the sample there were no cases where the price was zero and few where the Price = MaxPrice. Use of an untransformed variable which include observations where Price $=$ MaxPrice provides results consistent with those presented here. Similar results are also obtained if I exclude 55 observations representing high value outlying values of this variable which occur when Price is close to MaxPrice.

${ }^{54}$ I use a single random forecast per analyst during the period 30-60 days prior to the earnings announcement to generate the ACEF Target variable. Alternative forecast horizons provide similar but slightly weaker results suggesting that managers are using price reductions to meet or beat forecasts from this horizon period more than those of other horizon periods.

${ }^{55}$ See Burgstahler and Dichev (1997) for a further discussion of the motivation to manage earnings past miscellaneous benchmarks.

${ }^{56}$ The $10 \%$ band is used here in preference to a $5 \%$ band due to the relative lack of observations in the $0-5 \%$ range below the prior year. Use of a 10\% band for JustBeatQEnd does not materially change the results.
} 
Use of monthly fixed effects could obscure the hypothesized inter-temporal persistence and competitor pricing effects. Therefore, the models are estimated including three additional control variables using

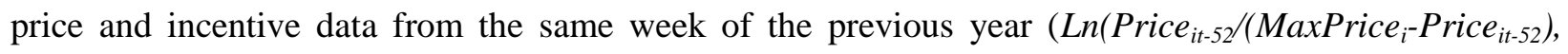
JustBeatQEnd $_{i t-52}$ and JustMissQEnd ${ }_{i t-52}$ ) to control for seasonality.

The frequency of observations where firms are predicted to discount prices to meet earnings targets varies considerably by month and year. On average, approximately $11 \%(17 \%)$ of observations occur in quarters where firms just beat their EPS (ACEF) Target as shown in table 1. Similarly, the 10\% (9\%) of observations occur in quarters where firms just miss the EPS (ACEF) Target. The band has been widened from $5 \%$ to $10 \%$ for firms missing the benchmarks to ensure adequate numbers of observations to estimate all models.

The results of the Earnings Management tests using the same quarter's EPS from the prior year as the EPS Target are presented in table 3, column $1 .^{57}$ The findings indicate that firms that just meet or beat last year's quarterly EPS have average price declines of $10 \%\left(\beta_{1}=-0.429\right)$ relative to other firms in the last month of the fiscal quarter. In contrast, firms that just miss last year's quarterly EPS do not show any changes in pricing behavior at the fiscal quarter-end ( $\beta_{2}$ not significantly different from zero). Note that $\beta_{1}$ is significantly different from $\beta_{2}$ in table 3 , column 1 implying that firms just beating their EPS Target reduce prices more than those firms which just beat their targets. The distribution of price for the full range of quarterly EPS differences from the prior year can be seen in the spline regression shown in figure 6. There are noticeable price reductions for firms which just beat their earnings targets.

The results of the Earnings Management tests using Analyst Consensus Forecast of Earnings as the ACEF Target are presented in table 4, column 1 . The findings indicate that firms that just meet or beat the ACEF Target have average price declines of $15 \%\left(\beta_{1}=-0.298\right)$ in the last month of the fiscal quarter. In

\footnotetext{
${ }^{57}$ It is theoretically possible that the choice of fiscal year-end makes several of the variables in the model endogenous leading to biased coefficients. Re-estimation of this, and subsequent models using overall monthly sales volumes as an instrument for the probability of a fiscal quarter-end does not materially change the results.
} 
contrast, firms that just miss the ACEF Target increase prices by approximately $15 \%\left(\left(\beta_{2}=0.655\right)^{58}\right.$ at the fiscal quarter-end. The justification for such price increases is unclear but, given that this pricing behavior boosts earnings the following period, it is consistent with an earnings smoothing hypothesis.

These findings are consistent with the survey evidence of Graham, Harvey and Rajgopal (2005) that managers take real actions to meet prior year EPS as well as analyst expectations.

\subsection{Abnormal Inventory Levels}

One potential alternative explanation for the above findings is that firms reduce prices to manage excess inventory levels rather than to manage earnings. Inventory levels are likely to be correlated to historic performance, giving rise to the possibility of a correlated omitted variable problem. The analysis is therefore repeated incorporating two proxies for the incentive to manage excess inventory as additional control variables, one at the firm level and one at the product level. The first measure used is defined as InventoryChange $_{t}=\left(\frac{\text { Inventory }_{t-1}}{\text { Sales }_{t-1}}-\frac{\text { Inventory }_{t-5}}{\text { Sales }_{t-5}}\right) / \frac{\text { Inventory }_{t-5}}{\text { Sales }_{t-5}} \cdot{ }^{59}$ This measures the inventory change (in number of days sales) over the twelve months ending at the beginning of the quarter of interest.

The inclusion of this variable allows testing of Hypothesis H3. If prices fall in periods following upward spikes in inventory, a negative value for $\beta_{8}$, the coefficient on InvestoryChange, should be observed in the following regression:

$$
\begin{gathered}
\operatorname{Ln}\left(\frac{\text { Price }_{i t}}{\text { MaxPrice }_{i}-\text { Price }_{i t}}\right)=\alpha+\beta_{1} \text { JustBeatQEnd }_{i t}+\beta_{2} \text { JustMissQEnd }_{i t}+\beta_{4} \operatorname{Ln}\left(\frac{\text { Price }_{i t}-52}{\text { MaxPrice }_{i} \text {-Price }_{i t}-52}\right)+ \\
\beta_{5} \text { JustBeatQEnd }_{i t-52}+\beta_{6} \text { JustMissQEnd }_{i t-52}+\beta_{8} \text { InventoryChange }_{i t}+\varepsilon_{i t} .
\end{gathered}
$$

The results of these estimations with respect to EPS Targets and ACEF Targets are shown in column 2 of tables 3 and 4, respectively. In both settings, increases in inventory levels observed at the beginning of

\footnotetext{
${ }^{58}$ These results are robust to the inclusion of additional control variables used in subsequent tests.

${ }^{59}$ Use of different inventory change measures (including dummies for specific ranges and contemporaneous effects) have varying explanatory power but do not materially change the significance of the other coefficients of interest in the regressions.
} 
the quarter are associated with price increases $\left(\beta_{8}>0\right)$, not the predicted price reduction. This may be the result of inventory increases being associated with increased prices and level of service, but is inconsistent with a theory of price reductions being used to counteract increases in inventory levels.

The InventoryChange variable is derived from quarterly data at the corporate level which is likely to be a noisy proxy for the incentive to manage product level inventory. A simple inventory prediction model is therefore developed to estimate incentive to manage excess inventory at the product level.

Expected sales volumes are estimated using the previously estimated model shown in table 2 with additional fixed effects for each of the individual UPC codes in the sample:

$\operatorname{Ln}\left(\right.$ WeeklyUnitsSold $\left._{i t}\right)=\alpha+\sum_{j=-1}^{1} \beta_{j} \operatorname{Ln}\left(\frac{\text { Price }_{i, t+j}}{\text { MaxPrice }_{i}-\text { Price }_{i, t+j}}\right)+\sum_{j=1}^{12} \gamma_{j}$ Month $_{j}+\operatorname{Ln}\left(\frac{\text { Price }_{i, t}}{\text { MaxPrice }_{i}-\text { Price }_{i, t+j}}\right) * I+\sum_{j} \delta_{j} U P C_{j}+\varepsilon_{i t} 60$

where $U P C_{j}$ are fixed effects for the different UPCs. The residuals can be considered as 'unexpected' sales and hence lagged residuals can be considered as a proxy for 'unexpected' inventory levels at the product level. ${ }^{61}$

The regression model estimated above is refined by adding lagged UnexpectedInventory (scaled by annual sales) as an alternative control variable as follows:

$$
\begin{aligned}
& \operatorname{Ln}\left(\frac{\text { Price }_{i t}}{\text { MaxPrice }_{i} \text {-Price }_{i t}}\right)=\alpha+\beta_{1} \text { JustBeatQEnd }_{i t}+\beta_{2} \text { JustMissQEnd }_{i t}+\beta_{4} \operatorname{Ln}\left(\frac{\text { Price }_{\text {it }-52}}{\text { MaxPrice }_{i}-\text { Price }_{\text {it }-52}}\right)+ \\
& \beta_{5} \text { JustBeatQEnd }_{i t-52}+\beta_{6} \text { JustMissQEnd }_{i t-52}+\beta_{9} \text { UnexpectedInventoryChange }_{i t}+\varepsilon_{i t} \text {. }
\end{aligned}
$$

If prices fall in periods of unexpectedly high inventory, a negative value for $\beta_{9}$, the coefficient on UnexpectedInventory should be observed.

\footnotetext{
${ }^{60}$ A single period look forward/back model is used here as the two period anticipation model results in multiple lost observations due to data limitations and significantly weaker statistical significance. However, use of the two period look ahead / back model provides similar results with fewer observations. Use of one week look-back is also consistent with the minimum time required for firms to react and change prices within the system.

${ }^{61}$ Reported results include one week's lagged residuals. Use of additional lags provides no material additional information.
} 
The results of these estimations with respect to EPS Targets and ACEF Targets are shown in column 4 of tables 3 and 4, respectively. They show the coefficient on UnexpectedInventory is not significantly different from zero $\left(\beta_{9}=-1.602\right.$ for the EPS Target and -0.253 for beating the ACEF Target). ${ }^{62}$

The coefficients on the main variable of interest (JustBeatQEnd) in the test of Hypothesis $H 2$ are slightly, but not materially, changed with the inclusion of the Inventory related control variables by the addition of the inventory control variables. This suggests that the results of the earlier analyses relating to Earnings Management incentives persist after controlling for inventory management incentives. Exclusion of the JustBeatQEnd and JustMissQEnd variables from these estimations results in coefficient estimates for the UnexpectedInventory variable to be significantly different from zero (not reported).

Overall, these results suggest there may be some relation between inventory and price. However, either the proxies for inventory management incentives used here are weak or the relation is more complex than firms simply cutting prices to reduce excess inventory. This prevents us from drawing conclusions in relation to Hypothesis $H 3$ as to whether firms adjust prices when inventory levels are unusually high. In either case, results of the earlier analyses relating to Earnings Management incentives persist after controlling for inventory management incentives.

\subsection{Competitive Response}

Hypothesis $H 4$ proposes that competitor firms reduce prices when other firms within their industry are predicted to discount prices to manage earnings. To test this hypothesis, variations on the following regressions with respect to EPS and ACEF Targets are estimated:

\footnotetext{
${ }^{62}$ One limitation of the analysis is the endogenous nature of the demand and price models relating to the use of anticipated prices $\left(\right.$ Price $\left._{t+1}\right)$. Exclusion of these variables from the model does not materially change the coefficients of interest here.
} 


$$
\begin{aligned}
& \operatorname{Ln}\left(\frac{\text { Price }_{i t}}{\text { MaxPrice }_{i}-\text { Price }_{i t}}\right)=\alpha+\beta_{1} \text { JustBeatQEnd }_{i t}+\beta_{2} \text { JustMissQEnd }_{i t}+\beta_{3} \text { IncentivesofOthers }_{i t} \\
& +\beta_{4} \operatorname{Ln}\left(\frac{\text { Price }_{i t-52}}{\text { MaxPrice }_{i}-\text { Price }_{i t-52}}\right)+\beta_{5} \text { JustBeatQEnd }_{i t-52}+\beta_{6} \text { JustMissQEnd }_{i t-52}+\beta_{7} \text { IncentivesofOthers }_{i t-52}+\varepsilon_{i t}
\end{aligned}
$$

where IncentivesofOthers ${ }_{i t}$ equals the dollar market share of firms (excluding firm $i$ ) that have an incentive to manage earnings upwards in the current month as measured by having JustBeatQEnd equal to one. The variable would equal one if all firms in the industry (excluding firm $i$ ) are classified as having incentive to manage earnings to just beat the EPS (ACEF) Target and 0.5 if firms representing half of the industry (measured according to their market share) have such an incentive.

If firms decrease prices when they expect more of their competitors to be reducing prices in response to earnings management incentives, $\beta_{3}$ (IncentivesofOthers) will be negative. The results of these estimations are shown in column 4 of tables 3 and 4 , respectively. As predicted, the $\beta_{3}$ estimate is negative and significant in both model formulations. The median values of IncentivesofOthers, the market share of firms who have incentive to boost earnings (when non-zero), are $10 \%$ and $13 \%$ for EPS and ACEF Targets respectively. This implies that firms reduce prices by $10 \%\left(\beta_{3}=-2.472\right.$ in table 3 , column 4) and $2.6 \%\left(\beta_{3}=-0.697\right.$ in table 4 , column 4$)$ in periods when competitors are expected to manage earnings upwards in relation to prior year quarterly EPS targets or the ACEF Target respectively. ${ }^{63}$

The magnitude of the competitive response is larger than might be predicted based upon prior research of Steenkamp et al (2005) who show that that the predominant competitive response to price promotion is

63 Results of the following regression estimations incorporating the inventory related control variables used in tests of $H 3$ as well as the IncentivesofOthers variable are presented in tables 3 and 4, columns 5 and 6.

$$
\begin{aligned}
& \text { Ln }_{(}\left(\frac{\text { Price }_{i t}}{\text { MaxPrice }_{i}-\text { Price }_{i t}}\right)=\alpha+\beta_{1} \text { JustBeatQEnd }_{i t}+\beta_{2} \text { JustMissQEnd }_{i t}+\beta_{3} \text { IncentivesofOthers }_{i t}+\beta_{4} \text { Ln }_{(}\left(\frac{\text { Price }_{i t-52}}{\text { MaxPrice }_{i}-\text { Price }_{i t-52}}\right) \\
& +\beta_{5} \text { JustBeatQEnd }_{i t-52}+\beta_{6} \text { JustMiss QEnd }_{i t-52}+\beta_{7} \text { IncentivesofOthers }_{i t-52}+\beta_{8} \text { InventoryChang }_{i t-1}+\varepsilon_{i t} \\
& \operatorname{Ln}\left(\frac{\text { Price }_{i t}}{\text { MaxPrice }_{i}-\text { Price }_{i t}}\right)=\alpha+\beta_{1} \text { JustBeatQEnd }_{i t}+\beta_{2} \text { JustMissQEnd }_{i t}+\beta_{3} \text { IncentivesofOthers }_{i t}+\beta_{4} \text { Ln }_{(}\left(\frac{\text { Price }_{i t-52}}{\text { MaxPrice }_{i}-\text { Price }_{i t-52}}\right) \\
& +\beta_{5} \text { JustBeatQEnd }_{i t-52}+\beta_{6} \text { JustMissQEnd }_{i t-52}+\beta_{7} \text { IncentivesofOthers }_{i t-52}+\beta_{9} \text { UnexpectedInventory }_{i t-1}+\varepsilon_{i t}
\end{aligned}
$$

None of the variables of interest are materially different in these regression estimations compared to previously presented results. 
passive in nature. However, this difference may be explained by the predictability of these price promotions at the fiscal quarter end and the ability of competitors to respond accordingly.

Overall, these results are consistent with Hypothesis H4: that firms reduce prices when more of their competitors have incentive to do so.

\subsection{Competition Effects on the Costs of Real Earnings Management}

The analysis in section 4.2 suggests that it is costly overall to reduce prices ahead of the fiscal quarterend. However, that analysis is based on a model which assumes that competitors' prices and the firm's promotion strategy will be stable throughout the year. It does not fully account for the effects of competitor price changes observed in Section 4.5 above, nor does it account for the changes in promotional activity based upon the fiscal calendar or earnings management incentives presented in Chapman and Steenburgh (2008).

In this section I analyze the cost and benefits of a temporary price adjustment in a similar manner to section 4.2 but in a competitive environment. This incorporates additional variables associated with competitors' prices as well as the fiscal calendar and level of upward earnings management incentive across the market as a whole to proxy for changes in promotional activity. The model now estimates how demand is affected by:

- previous, current and future prices of the product with the indicator variable $I$ introduced in section 4.1 above to account for multi-week discounts;

- $\quad$ previous, current and future pricing of competing products; and

- fiscal quarter end and earnings management incentives across all firms in the market (as a proxy for changes in promotion behavior) interacted with both own price and competitor price.

This results in the estimation of the following regression: 


$$
\begin{aligned}
& \text { Ln }\left(\text { WeeklyUnitsSold }_{i t}\right)=\alpha+\sum_{j=-2}^{2} \beta_{j} \text { OwnPrice }_{i, t+j}+\beta_{3} \text { OwnPrice }_{i, t} * I+\sum_{j=-1}^{1} \varphi_{j} \text { CompetitorPrice }_{i, t+j} \\
& + \text { OwnPrice }_{i, t} *\left(\beta_{4} \text { QEnd }_{i, t}+\beta_{5} \text { HighInc }_{i, t}+\beta_{6} \text { QEnd } * \text { HighInc }_{i, t}\right) \\
& + \text { CompetitorPrice }_{i, t} *\left(\varphi_{2} \text { QEnd }_{i, t}+\varphi_{3} \text { HighInc }_{i, t}+\varphi_{4} \text { QEnd }^{*} \text { HighInc }_{i, t}\right) \\
& +\beta_{7} \text { QEnd }_{i, t}+\beta_{8} \text { HighInc }_{i, t}+\sum_{j=1}^{12} \gamma_{j} \text { Month }_{j}+\varepsilon_{i t}
\end{aligned}
$$

Where WeeklyUnitsSold $i t$ is the number of units of soup product $i$ sold in week $t$. OwnPrice Owit $_{\text {equals the }}$ scaled price of the product, $\operatorname{Ln}\left(\frac{\text { Price }_{i, t+j}}{\text { MaxPrice }_{i}-\text { Price }_{i, t+j}}\right)$ where Price $_{i, t}$ is the mean price at which product $i$ is offered in week $t$ and MaxPrice $_{i}$ is the maximum average weekly price at which product $i$ is offered during the sample period. I is a dummy variable equal to one if Price $_{i, t-1}<$ Price $_{i, t}$ and zero otherwise and is included to protect against potential model mis-specification if similar prices are observed in consecutive weeks. CompetitorPrice ${ }_{i, t}$ is the mean price of competing products measured as $\frac{1}{k-1} \sum_{l=1 \text { noti }}^{k} \operatorname{Ln}\left(\frac{\text { Price }_{l, t+j}}{\text { MaxPrice }_{l}-\text { Price }_{l, t+j}}\right)$ where $k$ is the number of products. QEnd is $_{i, t}$ is a dummy variable which equals one if the observation is in the last month of the fiscal quarter and zero otherwise. HighInc $c_{i, t}$ is a dummy variable which equals one if competitors have high incentive to accelerate earnings as measured by the value of IncentivesofOthers being greater than its median value of $13 \%$ and zero otherwise. ${ }^{64}$ Month represents dummy variables for each calendar month.

The results of this estimation are shown in Table 5. Compared to the previous analysis, there are no new coefficients which are statistically significant suggesting we cannot conclude there are any material changes in either demand levels or the elasticity of demand based upon the level of competition or time of year. However, the magnitude of the coefficients relating to quarter ends and greater earnings

\footnotetext{
${ }^{64}$ This represents a scenario in which competitors representing more than $13 \%$ share of the market (excluding the firm itself) have earnings management incentive.
} 
management incentives are consistent in sign with a slight increase in demand during periods where Chapman and Steenburgh (2008) shows increased promotion activities likely to occur.

More interesting is the effect of competitor pricing changes on demand. When considering a period of low earnings management incentive and stable prices from competitors, figure 7 shows the same patterns of sales volume (left side) and cumulative contribution (right side) associated with stable prices and a price discount as were seen in figure 4 above. Here we see the increase in demand during the price promotion period followed by a post-promotion dip resulting in an overall reduction in the cumulative contribution margin compared to the case where the firm maintains stable prices.

In contrast, when considering a period of high earnings management incentive across the market associated with competitors cutting prices, figure 8 compares the predicted sales volumes (left side) and cumulative contribution (right side) if the firm maintains stable prices to those if it discounts prices.

The right hand part of the figure shows that both courses of action (maintaining stable prices or discounting) result in an overall reduction in profits when compared to the scenario in which competitors do not reduce prices. However, the overall reduction in profits is almost unaffected by the firm's decision to reduce prices. In this scenario, the price discounting strategy results in increased earnings up to the end of the quarter as before but the effect on the following period is no worse overall compared to not cutting prices.

One surprising feature of the figure is the increase in sales volumes and contribution prior to the competitors' price reduction. Further analysis of the price path indicates that competitor prices are raised in the week just prior to a period of price reduction which may explain the apparent increases in sales volume for the firm under consideration just prior to the competitors' promotion. ${ }^{65}$

\footnotetext{
${ }^{65} \mathrm{~T}$-test results showing that prices increase just prior to the first observation of a price below the median for a particular product are not reported.
} 
Overall, this evidence allows the conclusion that short-term price reductions result in increased sales volumes over the sample period. These sales increases boost short-term earnings through the end of the promotion. In a scenario where competitors maintain stable prices, price reductions reduce long-term earnings as a result of the drop in sales following the promotion. If competitors reduce prices, a strategy associated with a short-term price reduction still results in increased sales volumes and short-term earnings through the end of the promotion. However, the reduction in long-term earnings may be no worse than it would have been if the firm had maintained stable prices.

\subsection{Importance of Soup to the Firm}

To consider whether the importance of soup and similar businesses to the firm affect the price changes observed when the firm (and its competitors) have earnings management incentives, I extend the analysis presented in section 4.4 above by incorporating an additional variable PercentofBusiness which represents the percentage of revenues associated with $\operatorname{soup}^{66}$ for each firm in the sample as disclosed in their business segment report contained in the $10-\mathrm{K}$ filing. For the firms in the sample, soup represents an average of $42 \%$ of sales with a range of $1-62 \%$ and a standard deviation of $22.5 \%$. This is then interacted with both the JustBeatQEnd and IncentivesofOthers variables to estimate the following regression

$$
\begin{aligned}
& \operatorname{Ln}\left(\frac{\text { Price }_{i t}}{\text { MaxPrice }_{t}-\text { Price }_{i t}}\right) \\
& =\alpha+\beta_{1} \text { JustBeatQEnd }_{i t}+\beta_{2} \text { JustMissQEnd }_{i t}+\beta_{3} \text { IncentivesofOther }_{i t} \\
& +\beta_{4} \operatorname{Ln}\left(\frac{\text { Price }_{i t-52}}{\text { MaxPrice }_{t}-\text { Price }_{i t-52}}\right)+\beta_{5} \text { JustBeatQEnd }_{i t-52}+\beta_{6} \text { JustMiss QEnd }_{i t-52} \\
& +\beta_{7} \text { IncentivesofOthers }_{i t-52}+\beta_{10} \text { PercentofBusiness } s_{i t} \\
& +\beta_{11} \text { PercentofBusiness }_{i t} * \text { JustBeatQEnd }{ }_{i t}+\beta_{12} \text { PercentofBusiness }_{i t} * \text { IncentivesofOthers }_{i t}+\varepsilon_{i t}
\end{aligned}
$$

The result of this estimation is shown in column 5 of table 3 . The positive value of $\beta_{10}$ implies that the mean value of $\operatorname{Ln}\left(\frac{\text { Price }_{\text {it }}}{\text { MaxPrice }_{t}-\text { Price }_{\text {it }}}\right)$ is higher for firms with a higher proportion of sales in the soup

\footnotetext{
${ }^{66}$ This often incorporates related businesses such as sauces and sometimes beverages.
} 
category ("High Soup Firms"). Given the method of variable definition, this suggests a reduced variance of prices for these firms. The negative and significant value of $\beta_{11}$ suggests that High Soup Firms use more price reductions for their soups when they have upwards earnings management incentives and, finally, the positive value of $\beta_{12}$ suggests that High Soup Firms react less strongly to their competitors earnings management incentives. This is consistent with the market leading firms such as Campbells seeking to act as price leaders in the category with the brands that are less important to their firms being more affected by competitive pressures.

\subsection{Persistence of Price Discounting Behavior}

Based on the simple examples presented in section 2.5 above, Hypothesis $H 5$ suggests that price reductions used at the end of a quarter to boost earnings temporarily lead to earnings reductions in future years, creating greater incentive for subsequent price discounts.

Persistence in Earnings Management incentives may be tested in two ways:

- by testing for serial correlation in the likelihood of a firm just beating its EPS Target. Analysis of the data reveals no evidence of such serial correlation. However, this may be due to the lack of long time series data.

- by examining price discounting behavior at the end of reporting periods following those during which a firm just beat its EPS or ACEF Target. Although this effect may be present in the quarter immediately following, it is difficult to separate the calendar seasonality effects and the earnings management behavior using the sample data. Therefore, I consider the effect at the fiscal quarter-end twelve months after a firm just beat its EPS or ACEF Target.

For this purpose, the results of the same analysis used to test Hypothesis $H 2$ presented in tables 3 and 4 are reused. 


$$
\begin{aligned}
\operatorname{Ln}\left(\frac{\text { Price }_{i t}}{\text { MaxPrice }_{i}-\text { Price }_{i t}}\right)=\alpha & +\beta_{1} \text { JustBeatQEnd }_{i t}+\beta_{2} \text { JustMissQEnd }_{i t}+\beta_{4} \operatorname{Ln}\left(\frac{\text { Price }_{i t-52}}{\text { MaxPrice }_{i}-\text { Price }_{i t-52}}\right) . \\
& +\beta_{5} \text { JustBeatQEnd }_{i t-52}+\beta_{6} \text { JustMissQEnd }_{i t-52}+\varepsilon_{i t}
\end{aligned}
$$

However, the focus now is on the $\beta_{5}$ and $\beta_{6}$ coefficients relating to the incentives in the prior year, JustBeatQEnd $_{t-52}$ and JustMissQEnd ${ }_{t-52}$, respectively.

The estimated coefficients on JustBeatQEnd $t_{t-52}\left(\beta_{5} \approx-0.2\right.$ in all model specifications of table 3) are negative and significantly different from zero in all tests relating to the EPS Target. For the EPS Target, price reductions of $10 \%$ at the time of the earnings management incentive are followed by price reductions of $7.0 \%$ and $1.5 \%$ in the two subsequent years. ${ }^{67}$ These effects are above and beyond the effects of any contemporaneous Earnings Management incentive for those years which are captured by

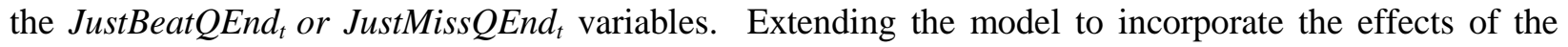
market share of other firms expected to be managing earnings from the previous year (IncentivesofOthers $t_{t-52}$ ) are presented in table 3, columns 4-7, and show a similar persistence trend in price discounting based upon competitor incentives.

Results relative to the ACEF Target are sensitive to the model specification and are shown in table 4. These show a strong response to the (IncentivesofOthers ${ }_{t-52}$ ) variable consistent with competitors repeating (and increasing) discounts in response to prior year incentives (and behavior) of other firms in the industry. The reversion to regular prices is faster $\left(\beta_{5} \approx-0.1\right.$ in table 4 , columns $\left.4-6\right)$ than for the EPS Target but discounting still appears persistent. However, this effect becomes insignificant when controlling for Unexpected Inventory suggesting that the persistence of price discounting associated with prior year ACEF Targets is mediated by UnexpectedInventory. Although not tested here, it is possible that competitors reduce prices slightly earlier than the firm being studied. This, in turn, leads to an upward spike in UnexpectedInventory just prior to the end-of-quarter price cut and the results observed.

\footnotetext{
${ }^{67}$ This price evolution is shown in figure 7 for a one-time Earnings Management Incentive in Year 3.
} 
Additional tests considering how prices are affected by preceding quarter EPS performance (results not reported) show that firms which just beat their EPS Target in one quarter reduce prices at the end of the following fiscal quarter.

Overall, this evidence suggests that price reductions associated with Earnings Management Incentives also affect pricing behavior three and twelve months later.

\section{Conclusion}

Using a new dataset of supermarket scanner data, this paper considers the effects of price discounting on current and future period earnings and the relation of earnings management incentives to both own-firm and competitors' pricing behavior. The results show that the price elasticity of demand for soup allows firms to increase short-term earnings by discounting prices. However, consistent with customer stockpiling soup during the discount periods, there is a drop in demand following the return to regular pricing which reduces earnings in the following period. This subsequent reduction in earnings is material and may be as much as twice the benefit gained during the price promotion.

Consistent with analytical models of incentive-motivated behavior and the survey evidence of Graham, Harvey and Rajgopal (2005), this evidence suggests that firms discount prices to meet prior year quarterly earnings as well as analyst expectations. Sample firms who just beat these targets reduced prices by an average of $10-15 \%$ in the final month of the fiscal quarter.

The results indicate that the effects of real earnings management are not restricted to firms with increased earnings management incentives. Tests of how competitors respond to the earnings management incentives of other firms in their industry show competitors reducing prices when more of the other firms within their industry have incentive to manage earnings. This effect is above and beyond the price reductions predicted based upon their own incentives. 
This price discounting behavior appears to be persistent. Although the data show no evidence of serial correlation in the likelihood of being classified as having strong earnings management incentives, price reductions associated with earnings management incentives around prior year EPS Targets are partially repeated in twelve months with an initial $10 \%$ price reduction at the time of the earnings management incentive being followed by price reductions of $7 \%$ and $1.5 \%$ twelve and twenty-four months later.

Overall, these findings suggest that firms discount prices to achieve earnings benchmarks and indicate these actions span multiple reporting periods and also affect competitor pricing behavior. 


\section{Appendix 1: The Effects on Profitability of Price Reductions}

In these calculations, I use a regression model similar to the one presented in table 2, column 5, but with the simple scaling of Price by MaxPrice ${ }^{68}$ to estimate the effect on demand of a price change as follows:

$\operatorname{Ln}\left(\right.$ WeeklyUnitsSold $\left._{i t}\right)=\alpha+\sum_{j=-2}^{2} \beta_{j} \operatorname{Ln}\left(\frac{\text { Price }_{i, t+j}}{\text { MaxPrice }_{i}}\right)+\beta_{3} \operatorname{Ln}\left(\frac{\text { Price }_{i, t}}{\text { MaxPrice }_{i}}\right) * I+\sum_{j=1}^{12} \gamma_{j}$ Month $_{j}+\varepsilon_{i t}$

Where $I$ is a dummy variable which equals one if Price $_{i, t-1}$ is less than Price $_{i, t}$ and zero otherwise.

This results in the following coefficient estimates and the graphics shown in figures 3 and 4.

Ln(Price $t_{t-2}$ MaxPrice) $\beta_{-2}$

0.095

Ln(Price t- $/$ MaxPrice) $\beta_{-1}$

0.419

Ln(Price, MaxPrice) $\beta_{0}$

$-1.602$

Ln(Price $_{t+1} /$ MaxPrice) $\beta_{1}$

$-0.155$

Ln(Price ${ }_{t+2} /$ MaxPrice) $\beta_{2}$

0.155

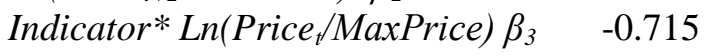

Constant

0.924

${ }^{68}$ The simplified scaling of the variable is used here to facilitate interpretation. 


\section{The Effects of a 15\% Price Reduction Lasting One Week}

For a one-week $15 \%$ price reduction in week $t=4$, with prices falling from 1.00 to 0.85 .

\begin{tabular}{|l|r|r|r|r|r|r|r|}
\hline Week & 1 & 2 & 3 & 4 & 5 & 6 & 7 \\
\hline Price $p$ & 1.00 & 1.00 & 1.00 & $\mathbf{0 . 8 5}$ & 1.00 & 1.00 & 1.00 \\
\hline Demand $v$ & 2.52 & 2.46 & 2.58 & 3.27 & 2.35 & 2.48 & 2.52 \\
\hline Revenue $=p^{*} v$ & 2.52 & 2.46 & 2.58 & 2.78 & 2.35 & 2.48 & 2.52 \\
\hline Contribution $=(p-c 1)^{*} v$ & 1.65 & 1.60 & 1.69 & 1.64 & 1.54 & 1.62 & 1.65 \\
\hline $\begin{array}{l}\text { Cumulative Change in Contribution } \\
\text { from Constant Price (with } c=c 1)\end{array}$ & 0.00 & -0.04 & 0.00 & 0.00 & -0.11 & -0.13 & -0.13 \\
\hline & & & & & & & \\
\hline Contribution = $(p-c 2)^{*} v$ & 2.06 & 2.01 & 2.11 & 2.18 & 1.92 & 2.03 & 2.06 \\
\hline $\begin{array}{l}\text { Cumulative Change in Contribution } \\
\text { from Constant Price (with } c=c 2)\end{array}$ & 0.00 & -0.05 & 0.00 & 0.12 & -0.01 & -0.04 & -0.04 \\
\hline & & & & & & & \\
\hline Contribution = $(p-c 3)^{*} v$ & 2.26 & 2.20 & 2.32 & 2.44 & 2.11 & 2.23 & 2.26 \\
\hline $\begin{array}{l}\text { Cumulative Change in Contribution } \\
\text { from Constant Price (with } c=c 3)\end{array}$ & 0.00 & -0.06 & 0.00 & 0.18 & 0.03 & 0.00 & 0.00 \\
\hline
\end{tabular}

Where $c l=34.7 \%, c 2=18.2 \%$ and $c 3=10.3 \%$ of regular price. These figures are chosen so that cumulative change in contribution is zero if $c=c 1$, cumulative change in contribution is $0.5 \%$ of quarterly contribution through the end of the promotion if $c=c 2$ and the overall cost of the promotion is zero if $c=c 3$

Quarterly 'contribution' can be increased by $0.5 \%$, Gross Profit increased by $0.6 \%$ and EPS increased by $2.5 \%$ if marginal costs are $18.2 \%$, gross margin is $68.1 \%$ and net margin is $16.4 \% .^{69}$

Cumulative Change in Contribution $=0.12=0.5 \% *(1-18.2 \%) * 2.52 * 12$.

Cumulative Change in Gross Margin $=0.12=0.6 \% * 68.1 \% * 2.52 * 12$.

Cumulative Change in EPS $=0.12=2.5 \% * 16.4 \% * 2.52 * 12$.

${ }^{69}$ These changes are highly sensitive to changes in assumption on margins and operating leverage. 


\section{The Effects of a 15\% Price Reduction Lasting Two Weeks}

For a two-week $15 \%$ price reduction in weeks $t=4$ and $t=5$, with prices falling from 1.00 to 0.85

\begin{tabular}{|c|c|c|c|c|c|c|c|c|}
\hline Week & 1 & 2 & 3 & 4 & 5 & 6 & 7 & 8 \\
\hline Price $p$ & 1.00 & 1.00 & 1.00 & 0.85 & 0.85 & 1.00 & 1.00 & 1.00 \\
\hline Demand $v$ & 2.52 & 2.46 & 2.52 & 3.35 & 3.05 & 2.32 & 2.48 & 2.52 \\
\hline Revenue $=p * v$ & 2.52 & 2.46 & 2.52 & 2.85 & 2.60 & 2.32 & 2.48 & 2.52 \\
\hline Contribution $=(p-c 4) * v$ & 1.65 & 1.60 & 1.65 & 1.69 & 1.54 & 1.51 & 1.62 & 1.65 \\
\hline $\begin{array}{l}\text { Cumulative Change in Contribution } \\
\text { from Constant Price (with } c=c 4 \text { ) }\end{array}$ & 0.00 & 0.04 & 0.04 & 0.00 & $0.1 \overline{1}$ & 0.24 & 0.27 & 0.27 \\
\hline Contribution $=(p-c 5) * v$ & 2.05 & 2.00 & 2.05 & 2.22 & 2.02 & 1.88 & 2.02 & 2.05 \\
\hline $\begin{array}{l}\text { Cumulative Change in Contribution } \\
\text { from Constant Price (with } c=c 5 \text { ) }\end{array}$ & 0.00 & 0.05 & 0.05 & 0.12 & 0.10 & 0.07 & $0.10^{-}$ & $0.10^{-}$ \\
\hline Contribution $=(p-c 6) * v$ & 2.28 & 2.22 & 2.28 & 2.53 & 2.30 & 2.09 & 2.24 & 2.28 \\
\hline $\begin{array}{l}\text { Cumulative Change in Contribution } \\
\text { from Constant Price (with } c=c \sigma \text { ) }\end{array}$ & 0.00 & 0.06 & 0.06 & 0.19 & 0.22 & 0.04 & 0.00 & 0.00 \\
\hline
\end{tabular}

Where $c 4=34.7 \%, c 5=18.2 \%$ and $c 6=9.7 \%$ of regular price. These figures are chosen so that cumulative change in contribution through the end of the promotion is zero if $c=c 4$, cumulative change in contribution is $0.5 \%$ of quarterly contribution through the end of the promotion if $c=c 5$ and the overall cost of the promotion is zero if $c=c 6$

Quarterly 'contribution' can be increased by $0.5 \%$, Gross Profit increased by $0.6 \%$ and EPS increased by $2.5 \%$ if marginal costs are $18.7 \%$, gross margin is $67.7 \%$ and net margin is $16.3 \% .^{70}$

Cumulative Change in Contribution $=0.12=0.5 \% *(1-18.7 \%) * 2.52 * 12$.

Cumulative Change in Gross Margin $=0.12=0.6 \% * 67.7 \% * 2.52 * 12$.

Cumulative Change in EPS $=0.12=2.5 \% * 16.3 \% * 2.52 * 12$.

\footnotetext{
${ }^{70}$ These changes are highly sensitive to changes in assumption on margins and operating leverage.
} 


\section{Appendix 2: Variable Definitions}

IncentivesofOthers measures the dollar market share in the relevant month (excluding product $i$ ) of firms with JustBeatQEnd equaling one.

IncentivesofOthers $_{t-52}$ is a variable which equals the value of IncentivesofOthers one year prior to the observation.

Indicator is a dummy variable equal to one if Price $_{i, t-1}<$ Price $_{i, t}$ and zero otherwise.

Inventory is the level of Inventory at the end of the quarter as stated in the corporation's SEC filings.

Inventory $y_{t-1}$ is the level of Inventory at the end of the preceding fiscal quarter as stated in the corporation's SEC filings.

Inventory $_{t-5}$ is a variable which equals the value of Inventory $_{t-1}$ one year prior to the observation.

InventoryChange $_{t}=\left(\frac{\text { Inventory }_{t-1}}{\text { Sales }_{t-1}}-\frac{\text { Inventory }_{t-5}}{\text { Sales }_{t-5}}\right) / \frac{\text { Inventory }_{t-5}}{\text { Sales }_{t-5}}$

Inventory Change $t_{t-52}$ equals the value of InventoryChange one year prior to the observation.

JustBeatQEnd is a dummy variable which equals one if the quarterly EPS for the manufacturing firm is 0$5 \%$ above a) the EPS figure from the same quarter in the previous year; or b) the Consensus Earnings Forecasts obtained as the mean forecast for the quarter estimated by analysts over the period 30-60 days prior to the end of the quarter, and the transaction occurs in the last month of the manufacturer's fiscal quarter, zero otherwise.

JustBeatQEnd $t_{t-52}$ is a variable which equals the value of JustBeatQnd one year prior to the observation.

JustMissQEnd is a dummy variable which equals one if the quarterly EPS for the manufacturing firm is 0$5 \%$ below a) EPS figure from the same quarter in the previous year; or b) the Consensus Earnings Forecasts obtained as the mean forecast for the quarter estimated by analysts over the period 30-60 days prior to the end of the quarter, and the transaction occurs in the last month of the manufacturer's fiscal quarter, zero otherwise.

JustMissQEnd $_{t-52}$ equals the value of JustMissQEnd one year prior to the observation.

MaxPrice is the maximum price at which the product is sold in the store over the sample period.

Price $_{t}$ is the average price of the product being sold in week $t$.

Price $_{t-52}$ equals the value of Price $_{t}$ one year prior to the observation.

UnexpectedInventory is the estimate of the unexpected inventory level as defined in section 4.4

Weekly Units Sold is defined as the number of units of a particular UPC sold in a week. 


\section{Bibliography}

Arya, Anil, Jonathan Glover, and Shyam Sunder. "Earnings Management and the Revelation Principle." Review of Accounting Studies 3 no. 1-2 (1998): 7-34.

Baber, W., P. M. Fairfield, and J. A. Haggard. "The Effect of Concern About Reported Income on Discretionary Spending Decisions: the Case of Research and Development." The Accounting Review 66 no. 4 (1991): 818-829.

Baker, George, Robert Gibbons, and Kevin Murphy. "Relational Contracts and the Theory of the Firm." Quarterly Journal of Economics 117 (2002): 39-84.

Bartov, E. "The Timing of Asset Sales and Earnings Manipulation." The Accounting Review 68 no. 4 (1993): 840-855.

Beatty, Randolf, Emre Karaoglu, and Tatiana Sandino. "Benchmarking Against the Performance of High Profile 'Scandal' Firms.” AAA 2007 Financial Accounting \& Reporting Section (FARS) Meeting Papers, University of Southern California 2006 Working Paper. SSRN Web site. http://ssrn.com/abstract=930749.

Bens, D., V. Nagar, and M. H. F. Wong. "Real Investment Implications of Employee Stock Option Exercises." Journal of Accounting Research 40 no. 2 (2002): 359-406.

Berndt, Ernst R. The Practice of Econometrics: Classic and Contemporary. Reading, MA: AddisonWesley Publishing Company, 1991.

Blattberg, Robert, Gary Eppen and Joshua Lieberman. "A Theoretical and Empirical Evaluation of Price Deals for Consumer Nondurables.” Journal of Marketing 45 (1981): 116-129.

Borenstein, Severin and Andrea Shepard. "Dynamic Pricing in Retail Gasoline Markets." The RAND Journal of Economics 27 no. 3 (1996): 429-451.

Bradley, James R. and Bruce C. Arntzen. "The Simultaneous Planning of Production, Capacity, and Inventory in Seasonal Demand Environments.” Operations Research 47 no. 6 (1999): 795-806.

Bresnahan, Timothy F. "Competition and Collusion in the American Automobile Industry: The 1955 Price War.” The Journal of Industrial Economics 35 no. 4 (1987): 457-482.

Bruns, William J. and Kenneth A. Merchant. "The Dangerous Morality of Managing Earnings." Management Accounting 72 no. 2 (1990): 22-25.

Burgstahler, David and Ilia Dichev. "Earnings Management to Avoid Earnings Decreases and Losses." Journal of Accounting and Economics 24 no. 1 (1997): 99-126.

Bushee, Brian J. "The Influence of Institutional Investors on Myopic R\&D Investment Behavior." Accounting Review 73 no. 3 (1998): 305-333.

Campbell Soup Company, 19 May 2008, “Q3 Results Conference Call,” retrieved August 12, 2008, from http://www.shareholder.com/visitors/event/build2/mediapresentation.cfm?companyid=CPB\&med 
iaid=3148mediauserid5 $\&=3186908 \&$ TID $=385240743: 82 B 35 F E 2 F 9 E 43 D 27 C E 1 A 6 F C 92 D C 1 A$ C52\&popupcheck=0\&shexp=200808121225\&shkey $=9710057300 \mathrm{dc} 3836655445 \mathrm{c} 61 \mathrm{c} 879 \mathrm{~d} 42 \& \mathrm{pl}$ ayer $=1$

Chapman, Craig J. and Thomas J. Steenburgh, "An Investigation of Earnings Management through Marketing Actions." Harvard Business School Working Paper, No. 08-073, February 2008.

Che, Hai, K. Sudhir, and P. B. Seetharaman. "Bounded Rationality in Pricing under State Dependent Demand: Do Firms Look Ahead? How Far Ahead?" Journal of Marketing Research 44 no. 3 (2007): 434-449

Cheng, Shijun. "R\&D Expenditures and CEO Compensation." The Accounting Review 79 no. 2 (2004): 305-328.

Chintagunta P., V. Kadiyali and N. Vilcassim, "Empirical Analysis of Intertemporal Competitive Product Line Pricing Decisions: Lead Follow or Move Together?" Journal of Business 69 no. 4 (1996): 459-487.

. "Product Line Extensions and Competitive Market Interactions: An Empirical Analysis." Journal of Econometrics 89 (1999): 339-364.

Cohen, Daniel A., Aiyesha Dey, and Thomas Z. Lys (2008). "Real and Accrual-Based Earnings Management in the Pre- and Post-Sarbanes Oxley Periods." Accounting Review 83 no. 3 (2008): 757-787.

Dechow, Patricia, S. P. Kothari and Ross L. Watts. "The Relation Between Earnings and Cash Flows." Journal of Accounting and Economics 25 no. 2 (1998): 133-168.

Dechow, Patricia M. and Richard G. Sloan. "Executive Incentives and the Horizon Problem." Journal of Accounting and Economics 14 no. 1 (1991): 51-89.

Degeorge, François, Jayendu Patel, and Richard Zeckhauser. "Earnings Management to Exceed Thresholds." Journal of Business 72 no. 1 (1999): 1-33.

Demsetz, Harold and Kenneth Lehn. "The Structure of Corporate Ownership: Causes and Consequences." The Journal of Political Economy 93 no. 6 (1985): 1155-1177.

Docking, Diane S., Mark Hirschey, and Elaine Jones. "Information and Contagion Effects of Bank LoanLoss Reserve Announcements.” Journal of Financial Economics 43 no. 2 (1997): 219-239.

Durtschi, Cindy and Peter Easton. "Earnings Management? Shapes of the Frequency Distributions of Earnings Metrics are not Evidence Ipso Facto.” Journal of Accounting Research 43 no. 4 (2005): 557-592.

Dye, Ronald A. "Earnings Management in an Overlapping Generations Model.” Journal of Accounting Research 26 (1998): 91-119.

Ewert, Ralf and Alfred Wagenhofer. "Effects of Tightening Accounting Standards to Restrict Earnings Management." The Accounting Review 80 no. 4 (2005): 1101-1124. 
Fields, Thomas D., Thomas Z. Lys and Linda Vincent, "Empirical Research on Accounting Choice." Journal of Accounting and Economics 31 (2001): 255-307

Froot, K. A. "Consistent Covariance Matrix Estimation With Cross-Sectional Dependence and Heteroskedasticity in Financial Data." Journal of Financial and Quantitative Analysis 24 (1989): $333-355$.

Fudenberg, Drew and Jean Tirole. "Customer Poaching and Brand Switching." The RAND Journal of Economics 31 no. 4 (2000): 634-657.

_. "A Theory of Income and Dividend Smoothing Based on Incumbency Rents." Journal of Political Economy 103 no. 1 (1995): 75-93.

Gleason, Christi A., Nicole T. Jenkins, and W. Bruce Johnson. "The Contagion Effects of Accounting Restatements.” Accounting Review 83 no. 1 (2008): 83-110.

Goel, Anand Mohan and Anjan V. Thakor. "Why Do Firms Smooth Earnings?” Journal of Business 76 no. 1 (2003): 151-192.

Graham, John R., Campbell R. Harvey, and Shiva Rajgopal. "The Economic Implications of Corporate Financial Reporting." The Journal of Accounting and Economics 40 no. 1-3 (2005): 3-73.

Granger, Clive W. J. "Investigating Causal Relations by Econometric Methods and Cross-Spectral Methods.” Econometrica 34 no. 4 (1969): 424-438.

Green, Edward J. and Robert H. Porter. "Non-cooperative Collusion under Imperfect Price Information." Econometrica 52 no. 1 (1984): 87-100.

Gunny, Katherine A. "What Are the Consequences of Real Earnings Management?” Ph.D. diss., University of California, Berkeley, 2005.

Gupta, Sunil. "Impact of Sales Promotions on When, What, and How Much to Buy." Journal of Marketing Research 25 no. 4 (1988): 342-355.

Hanssens, Dominique M., Koen Pauwels, and S. Siddarth. "The Long-Term Effects of Price Promotions on Category Incidence, Brand Choice and Purchase Quantity." Journal of Marketing Research 39 no. 4 (2002): 421-439.

Healy, Paul M. "The Effect of Bonus Schemes on Accounting Decisions." Journal of Accounting and Economics 7 no. 1-3 (1985): 85-107.

, and James M.Wahlen. "A Review of the Earnings Management Literature and its Implications for Standard Setting." Accounting Horizons 13 no. 4 (1999): 365-383.

Herrmann, Don, Tatsuo Inoue, and Wayne B. Thomas. "The Sale of Assets to Manage Earnings in Japan.” Journal of Accounting Research 41 no. 1 (2003): 89-108. 
Huber, P. J. "The Behavior of Maximum Likelihood Estimates Under Nonstandard Conditions." Proceedings of the Fifth Berkeley Symposium on Mathematical Statistics and Probability, Berkeley, CA, 1 (1967): 221-223.

Kreps, D. M. and J. Sheinkman. "Quantity Pre-commitment and Betrand Competition Yield Cournot Outcomes.” RAND Journal of Economics 14 (1983): 326-337.

Lavelle, Louis. "The Case of the Corporate Spy.” BusinessWeek, November 26, 2001, pp. 56-58.

Macé, Sandrine and Scott A. Neslin. "The Determinants of Pre- and Post-Promotion Dips in Sales of Frequently Purchased Goods.” Journal of Marketing Research 41 no. 3 (2004): 339-350.

Maynard, Micheline and Jeremy W. Peters. "Big Drop in October for Detroit." The New York Times November 2, 2005.

McNichols, Maureen F. and G. Peter Wilson. "Evidence of Earnings Management from the Provision for Bad Debts." Journal of Accounting Research 26 (1988): 1-31.

Mizik, Natalie and Robert Jacobson. "Myopic Marketing Management: Evidence of the Phenomenon and Its Long-term Performance Consequences in the SEO Context." Marketing Science 26 no. 3 (2007): 361-379.

Myerson, R. "Incentive Compatibility and the Bargaining Problem." Econometrica 47 (1979): 61-74.

Narasimhan, Chakravarthi, Scott A. Neslin, and Subrata K. Sen. "Promotional Elasticities and Category Characteristics." Journal of Marketing 60 (1996): 17-30.

Nevo, Aviv. "Measuring Market Power in the Ready-to-Eat Cereal Industry." Econometrica 69 no. 2 (2001): 307-342.

Newey, W. K. and K. D. West. “A Simple, Positive Semi-Definite, Heteroskedasticity and Autocorrelation Covariance Matrix.” Econometrica 55 no. 3 (1987): 703-708.

Oberholzer-Gee, Felix and Julie Wulf. "Earnings Management from the Bottom Up: An Analysis of Division Manager Incentives.” 2006 Working Paper. http://www.scholar.google.com.

Oyer, Paul. "Fiscal Year Ends and Non-Linear Incentive Contracts: The Effect of Business Seasonality." Quarterly Journal of Economics 113 no. 1 (1998): 149-185.

Richardson, Scott, Siew Hong Teoh, and Peter D. Wysocki. "The Walk-down to Beatable Analyst Forecasts: The Role of Equity Issuance and Insider Trading Incentives." Contemporary Accounting Research 21 no. 4 (2004): 885-924.

Roychowdhury, Sugata. "Earnings Management Through Real Activities Manipulation.” Journal of Accounting and Economics 42 no. 3 (2006): 335-370.

Schipper, Katherine. “Commentary: Earnings Management.” Accounting Horizons 3 (1989): 91-102. 
Steenburgh, Thomas J. "Measuring Consumer and Competitive Impact with Elasticity Decompositions." Journal of Marketing Research 44 no. 4 (2007): 636-646.

Steenkamp, Jan-Benedict E. M., V. R. Nijs, D. M. Hanssens, and M. G. Dekimpe. "Competitive Reactions to Advertising and Promotion Attacks.” Marketing Science 24 no. 1 (2005): 35-54.

Stein, Jeremy C. "Efficient Capital Markets, Inefficient Firms: A Model of Myopic Corporate Behavior." The Quarterly Journal of Economics 104 no. 4 (1989): 655-669.

Stock, James H. and Mark W. Watson. Introduction to Econometrics. Boston, MA: Pearson/Addison Wesley, 2007.

Teoh, S. H., I. Welch, and T. J. Wong. "Earnings Management and the Long-Run Market Performance of Initial Public Offerings." The Journal of Finance 53 no. 6 (1988): 1935-1974.

Thomas, J. K. and H. Zhang. "Inventory Changes and Future Returns." Review of Accounting Studies 7 (2002): 163-187.

van Heerde, Harald J., Peter S. H. Leeflang, and Dick R. Wittink. "The Estimation of Pre- and PostPromotion Dips with Store-Level Scanner Data.” Journal of Marketing Research 37 no. 3 (2000): 383-395.

_. "Decomposing the Sales Promotion Bump with Store Data." Marketing Science 23 no. 3 (2004): 317-334.

Verrecchia, Robert E. “Discretionary Disclosure.” Journal of Accounting \& Economics 5 (1983): 179194.

• "Information Quality and Discretionary Disclosure.” Journal of Accounting \& Economics 12 (1990): 365-380.

White, H. "A Heteroskedasticity-Consistent Covariance Matrix Estimator and a Direct Test for Heteroskedasticity." Econometrica 48 (1980): 817-830.

Zang, Amy Y., "Evidence on the Tradeoff Between Real Manipulation and Accrual Manipulation" SSRN Working Paper: http://ssrn.com/abstract=961293, March 2007 
Figure 1: $\quad$ Fiscal Year-End Frequency Distribution for Companies in Sample (by UPC)

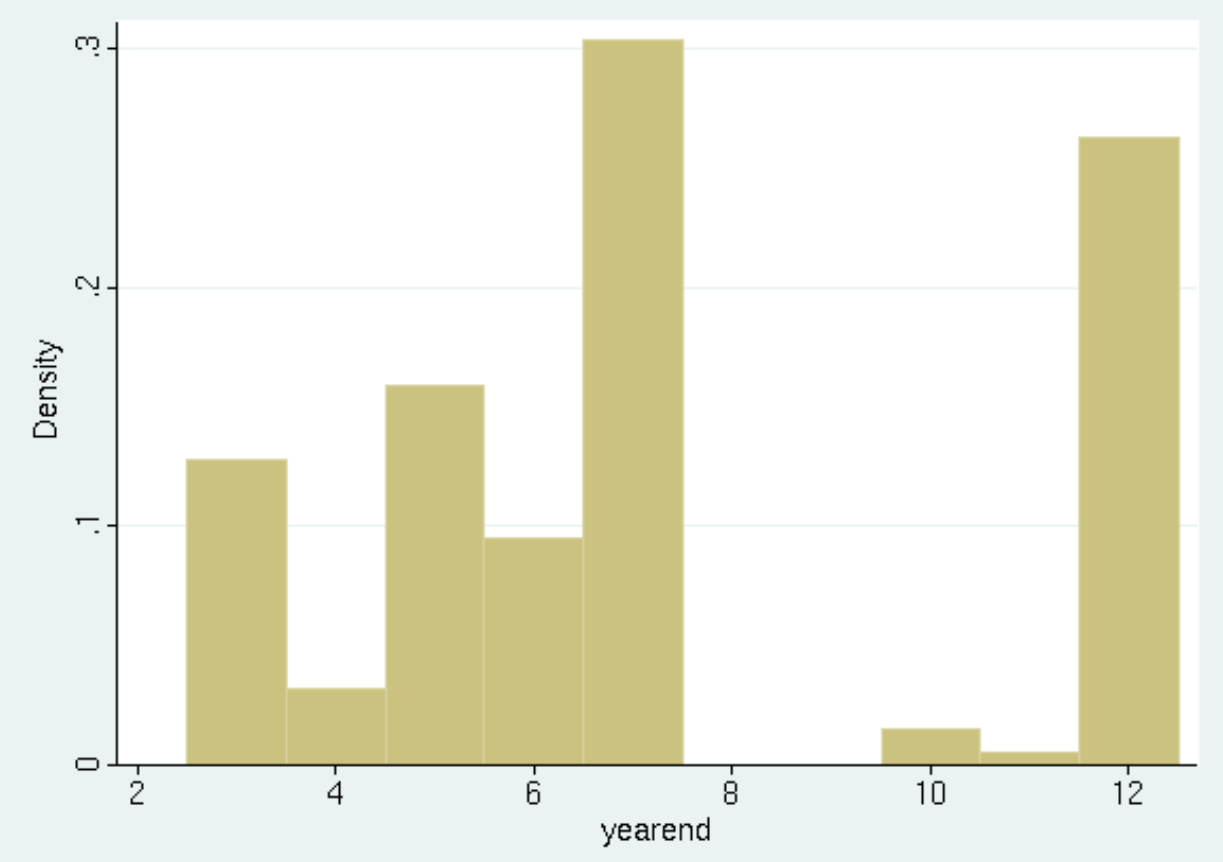

January is Month 1

Figure 2: $\quad$ Sales Frequency by Week

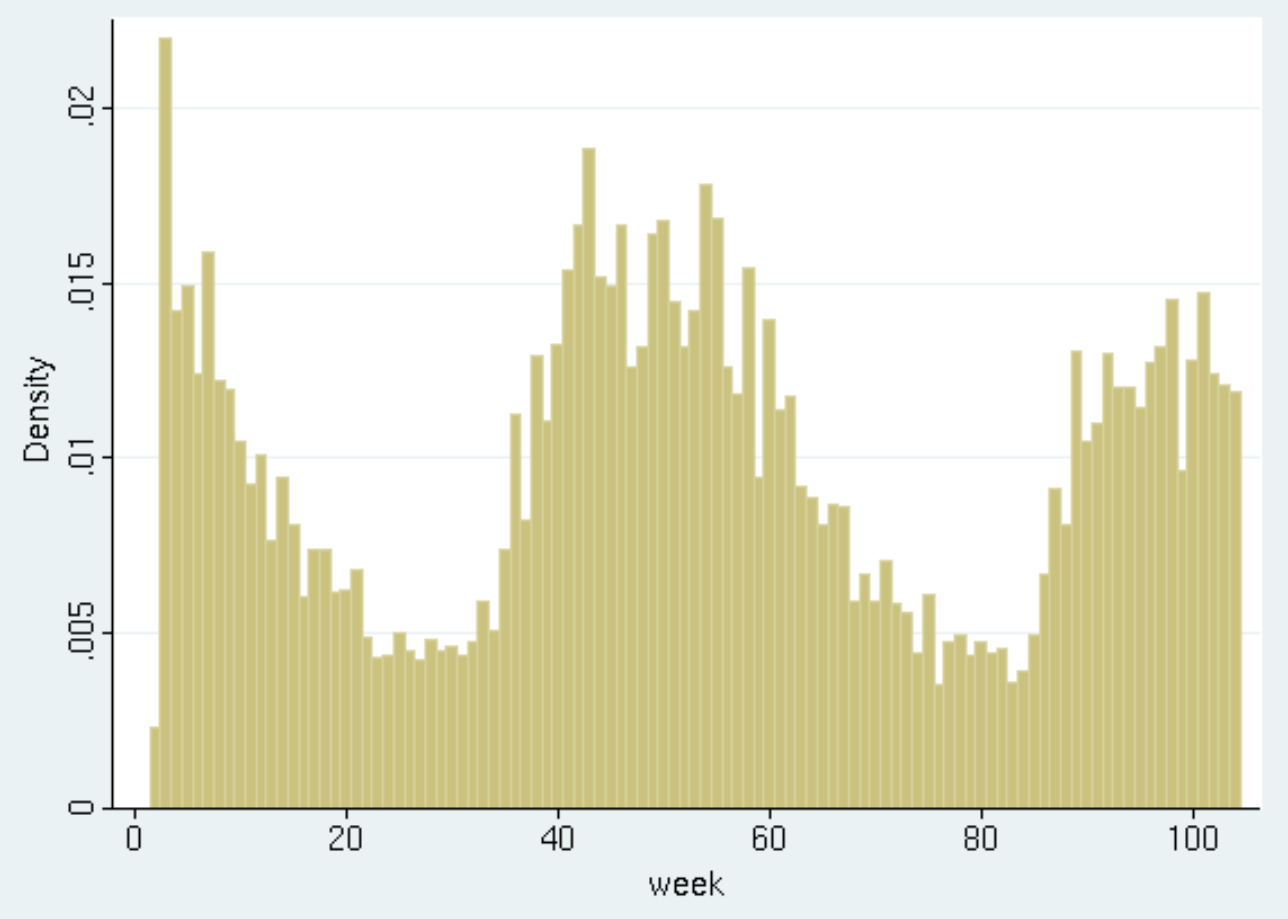

Week one is the beginning of the calendar year. 
Figure 3: $\quad$ The Effect on Sales Volumes, Revenues (Left) and Contribution (Right) of a One Week 50\%-Off Price Promotion in Period 6.
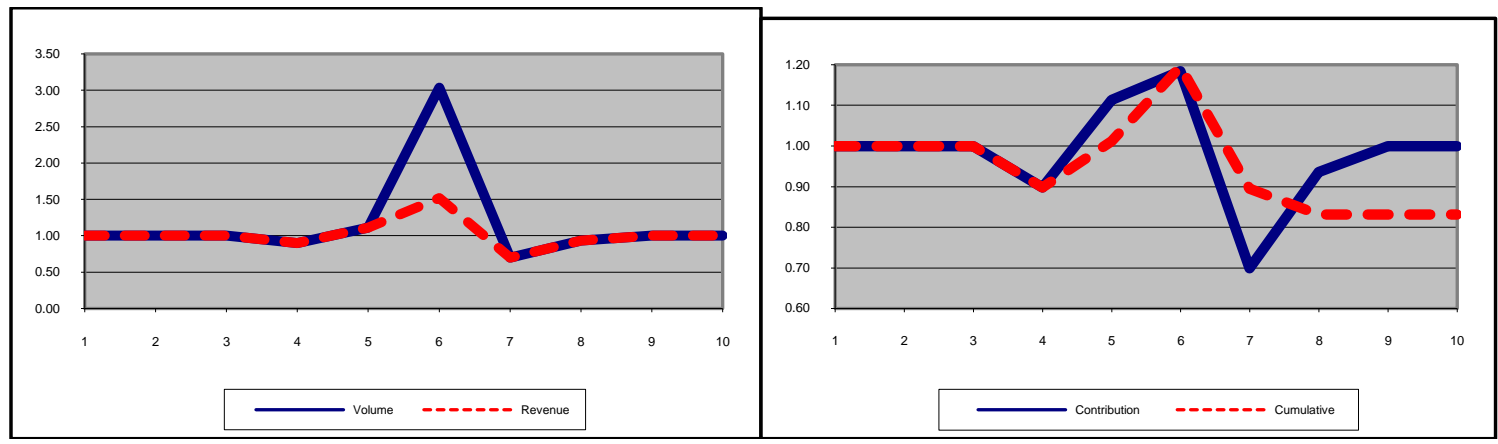

Regular Volume, Revenue and Contribution scaled to One.

Figure 4: $\quad$ The Effect on Sales Volumes, Revenues (Left) and Contribution (Right) of a TwoWeek 50\%-Off Promotion in Periods 5 \& 6
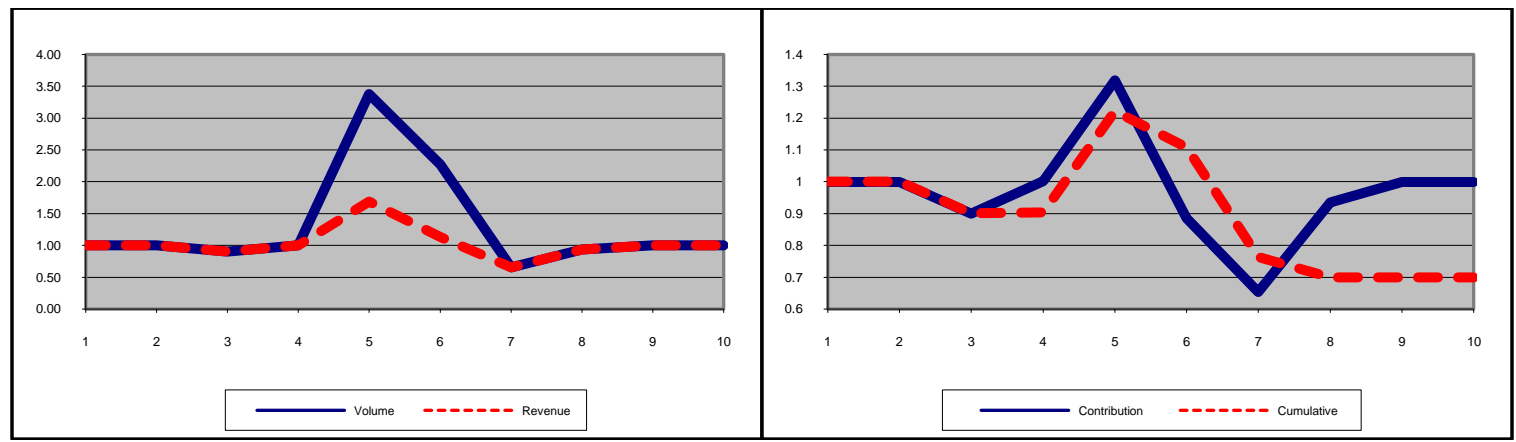

Regular Volume, Revenue and Contribution scaled to One.

Figure 5: $\quad$ The Effect on Contribution of a Two-Week 50\%-Off Promotion in Periods 5 \& 6 in Non-Quarter-End Weeks (left) and Quarter-End Weeks (right diagram)
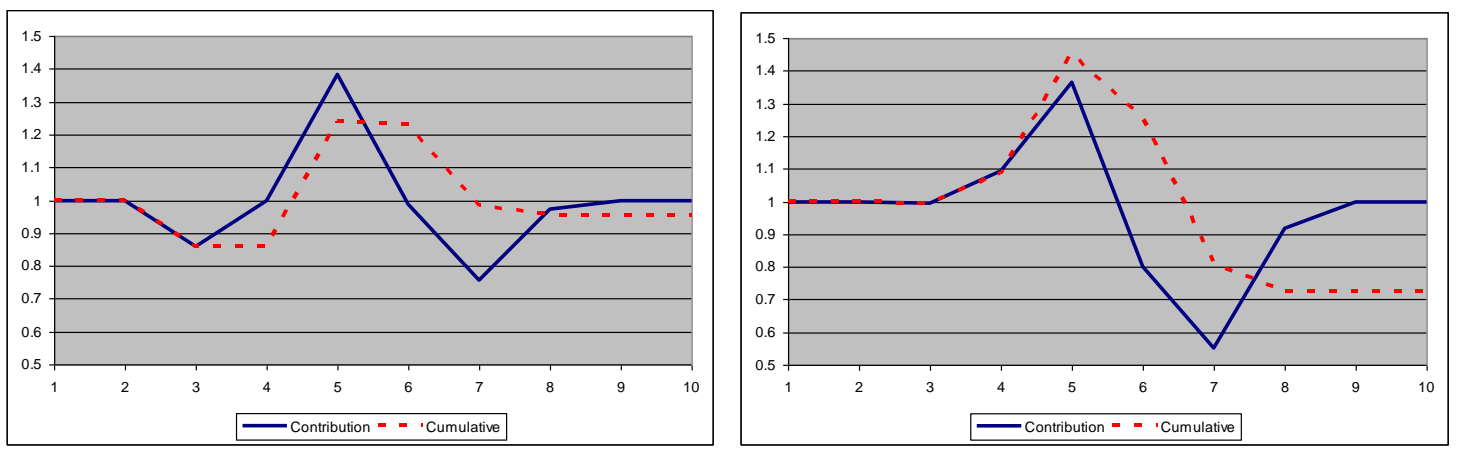
Figure 6: $\quad$ Spline Line Plot of Scaled Prices and Change in Quarterly EPS (compare to table 3 without additional control variables).

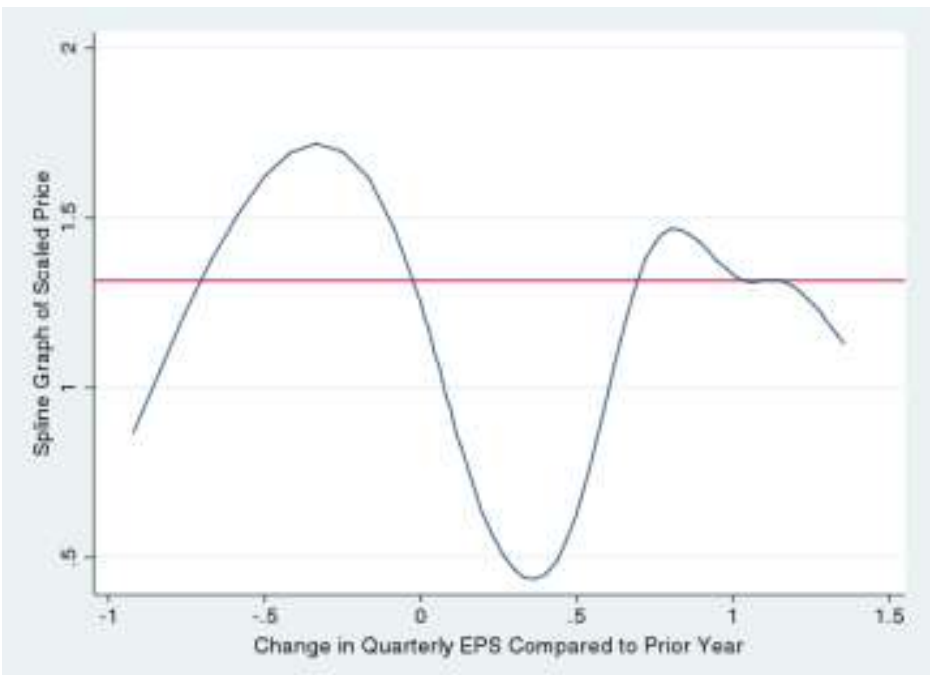

Figure 7: $\quad$ The Effect on Sales Volumes (Left) and Contribution (Right) of a Two-Week Promotion in Weeks 5 \& 6 with Competitors Maintaining Stable Prices
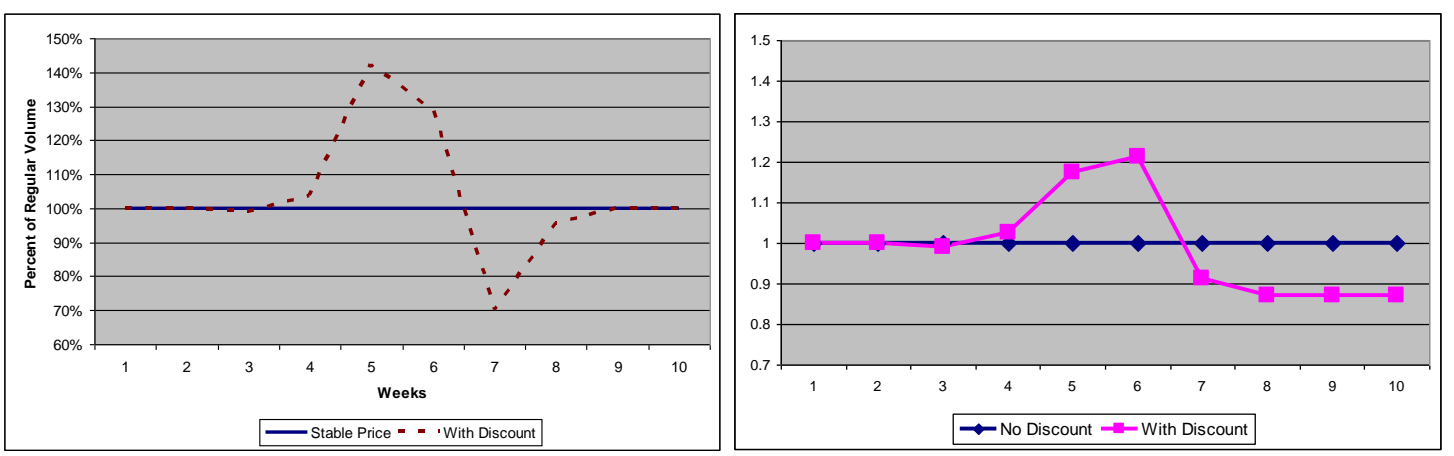

Figure 8: $\quad$ The Effect on Sales Volumes (Left) and Contribution (Right) of a Two-Week Promotion in Weeks 5 \& 6 with Competitors Reducing Prices in Weeks 5\&6
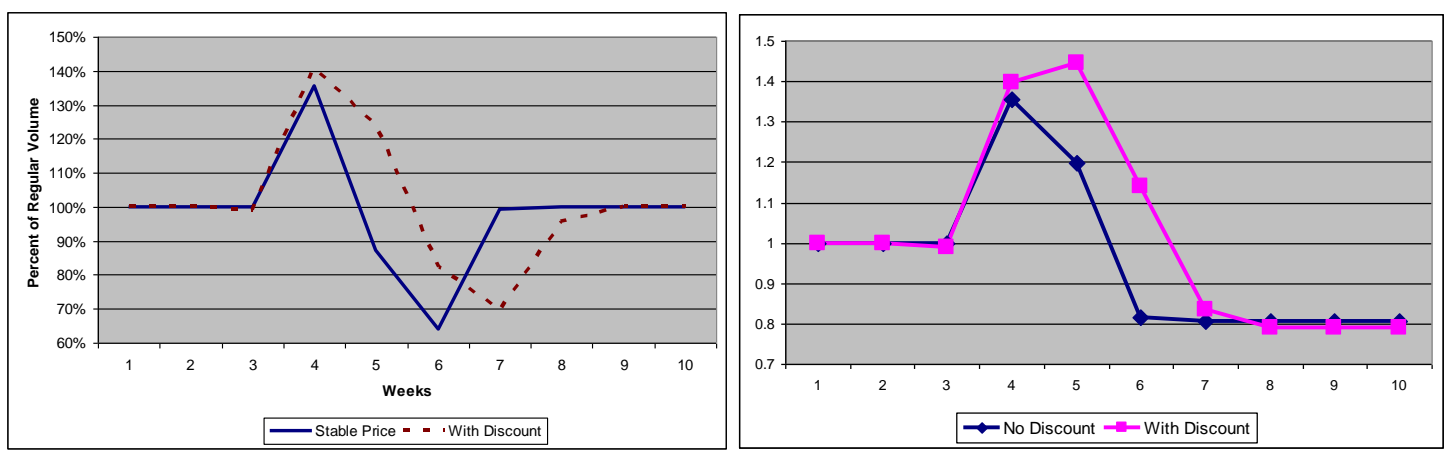
Figure 9: $\quad$ The Effect on Year-end Prices of an Earnings Management Incentive in Year 3 based upon table 3

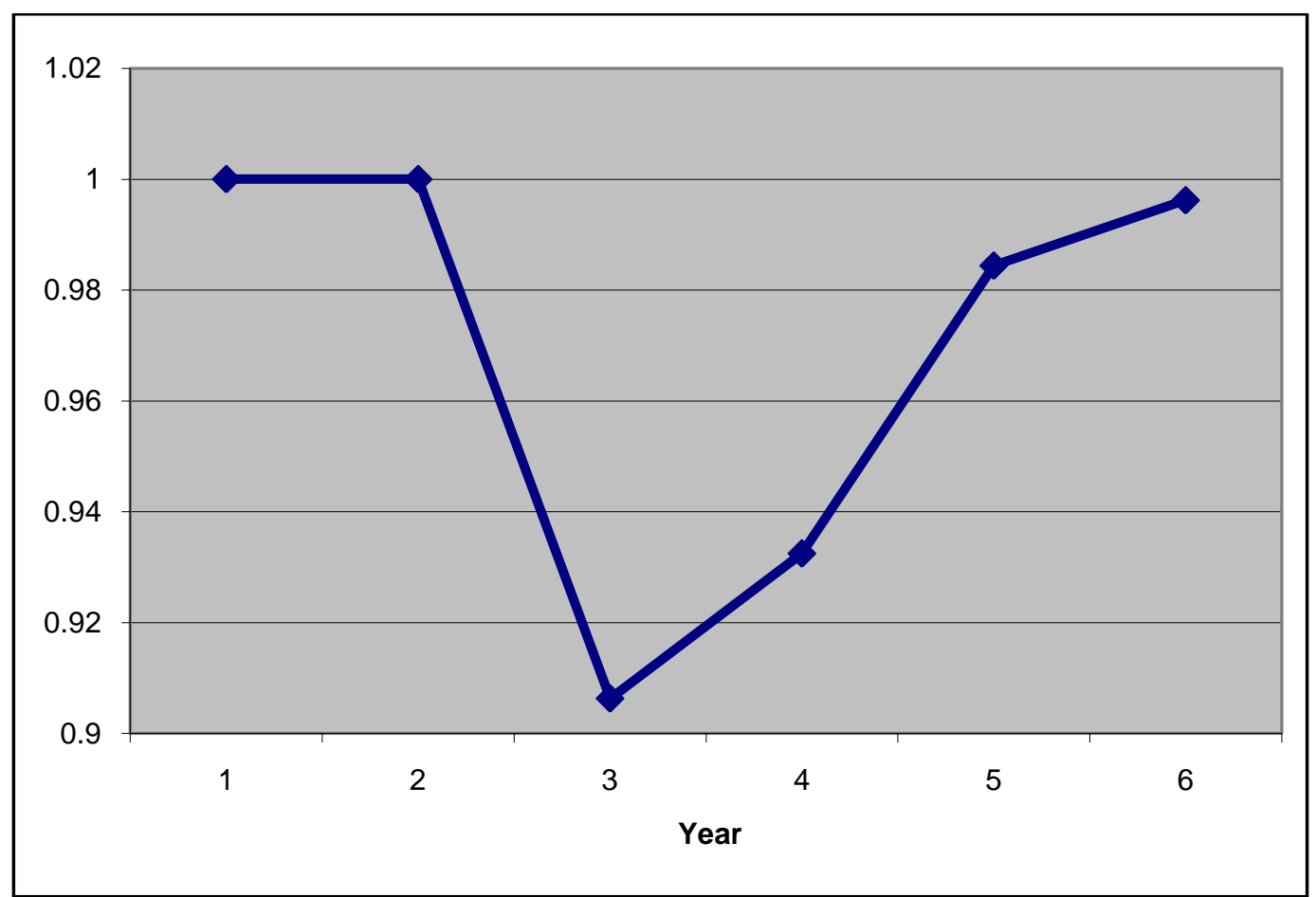

Regular Price scaled to One. 
Table 1: Summary Statistics

\begin{tabular}{|c|c|c|c|c|c|}
\hline Description of Data Availability & \multicolumn{2}{|c|}{ Full Sample } & \multicolumn{2}{|c|}{$\begin{array}{c}\text { Unique UPC } \\
\text { Week } \\
\text { Observations }\end{array}$} & $\begin{array}{c}\text { Used in } \\
\text { Table }\end{array}$ \\
\hline Individual Transactions in Database & $3,692,858$ & & & & \\
\hline Soup Purchases Contained in Database & 55,451 & $100.0 \%$ & 23,468 & $100.0 \%$ & \\
\hline Manufacturer is Known & 53,637 & $96.7 \%$ & 22,343 & $95.2 \%$ & \\
\hline Fiscal Year-end is Known & 52,138 & $94.0 \%$ & 21,401 & $91.2 \%$ & \\
\hline EPS Data & 42,434 & $76.5 \%$ & 16,895 & $72.0 \%$ & \\
\hline Analyst Forecasts & 41,726 & $75.2 \%$ & 11,289 & $48.1 \%$ & \\
\hline 1-week pre- \& post- prices & & & 8,302 & $35.4 \%$ & 2 \\
\hline 2- week pre- $\&$ post- prices & & & 4,807 & $20.5 \%$ & 2 \\
\hline Prior Year Prices and EPS Change & & & 4,435 & $71 \quad 18.9 \%$ & 3 \\
\hline Prior Year Prices and Analyst Forecasts & & & 2,543 & $7210.8 \%$ & 4 \\
\hline
\end{tabular}

\begin{tabular}{|c|c|c|c|c|}
\hline Variable & $\begin{array}{l}\text { Number } \\
\text { of Obs. }\end{array}$ & Mean & $\begin{array}{c}\text { Standard } \\
\text { Deviation }\end{array}$ & $\begin{array}{c}\text { Used in } \\
\text { Table }\end{array}$ \\
\hline Ln(Weekly Units Sold $)$ & 23,230 & 0.81 & 0.853 & 2 \\
\hline Used in table 2 & 8,302 & 1.19 & 0.944 & 2 \\
\hline Price & 23,230 & 1.81 & 0.892 & \\
\hline Used in table 2 & 8,302 & 1.59 & 0.756 & 2 \\
\hline Ln(Price,/MaxPrice-Price Pr $\left._{t}\right)$ & 21,062 & 1.31 & 1.220 & \\
\hline Used in table 2 & 8,302 & 1.20 & 0.969 & 2 \\
\hline JustBeat EPS Target ${ }^{73}$ & 16,900 & 0.11 & 0.312 & 3 \\
\hline JustMiss EPS Target & 16,900 & 0.10 & 0.303 & 3 \\
\hline IncentivesofOthers (EPS Target) ${ }^{74}$ & 2,969 & 0.26 & 0.174 & 3 \\
\hline JustBeat Analyst Consensus Earnings F/Cast & 10,851 & 0.17 & 0.377 & 4 \\
\hline JustMiss Analyst Consensus Earnings F/Cast & 10,851 & 0.09 & 0.284 & 4 \\
\hline IncentivesofOthers (Analyst Consensus) & 3,639 & 0.22 & 0.185 & 4 \\
\hline InventoryChange & 18,118 & -0.02 & 0.108 & $3-4$ \\
\hline UnexpectedInventory & 9,016 & 0.00 & 0.008 & $3-4$ \\
\hline
\end{tabular}

There is no material difference between the sub-samples presented above and those used due to data availability restrictions.

\footnotetext{
${ }^{71}$ Represents $37.6 \%$ of unique UPC Week observations during 2006.

${ }^{72}$ Represents $21.5 \%$ of unique UPC Week observations during 2006.

${ }_{74}^{73}$ Approximately $1 / 3$ of these observations fall into the last month of the fiscal quarter.

${ }^{74}$ When non-zero.

${ }^{75}$ When non-zero.
} 
Table 2: Impact of Marketing Actions on the Timing of Consumers' Purchases

\begin{tabular}{|c|c|c|c|c|c|c|}
\hline Dependent Variable & \multicolumn{6}{|c|}{ Ln(Weekly Units Sold $)$} \\
\hline Predicted Sign & $\begin{array}{c}\text { OLS } \\
1\end{array}$ & $\begin{array}{c}\text { OLS } \\
2\end{array}$ & $\begin{array}{c}\text { OLS } \\
3\end{array}$ & $\begin{array}{c}\text { OLS } \\
4\end{array}$ & $\begin{array}{c}\text { OLS } \\
5\end{array}$ & $\begin{array}{c}\text { OLS } \\
6\end{array}$ \\
\hline Ln$_{\left(\text {Price }_{t-2} /\left(\text { MaxPrice- } \text { Price }_{t-2}\right)\right) \beta_{-2}+}+$ & & & $\begin{array}{r}0.042 \\
(2.18)^{*}\end{array}$ & $\begin{array}{r}0.045 \\
(2.17)^{*}\end{array}$ & $\begin{array}{r}0.044 \\
(2.09)^{*}\end{array}$ & $\begin{array}{r}0.043 \\
(2.01)^{*}\end{array}$ \\
\hline Ln(Price ${ }_{t-1} /\left(\right.$ MaxPrice- $\left.\left._{\text {Price }}{ }_{t-1}\right)\right) \beta_{-1}$ & $\begin{aligned} & 0.058 \\
&(3.01)^{* *}\end{aligned}$ & $\begin{array}{r}0.060 \\
(3.11)^{* * *}\end{array}$ & $\begin{array}{r}0.036 \\
(2.02)^{*}\end{array}$ & $\begin{array}{r}0.040 \\
(2.15)^{*}\end{array}$ & $\begin{array}{r}0.064 \\
(2.59)^{* * *}\end{array}$ & $\begin{array}{r}0.063 \\
(2.56)^{* * * *}\end{array}$ \\
\hline Ln(Price $t /\left(\right.$ MaxPrice- Price $\left._{t}\right) \quad \beta_{0}$ & $\begin{array}{r}-0.293 \\
(-7.81)^{* *}\end{array}$ & $\begin{array}{r}-0.285 \\
(-7.69)^{* * *}\end{array}$ & $\begin{array}{r}-0.319 \\
(-6.31)^{* * *}\end{array}$ & $\begin{array}{r}-0.317 \\
(-6.22)^{* * * *}\end{array}$ & $\begin{array}{r}-0.340 \\
(-5.46)^{*}\end{array}$ & $\begin{array}{r}-0.343 \\
(-5.43)^{* * *}\end{array}$ \\
\hline Ln $_{\text {Price }}{ }_{t+1} /\left(\right.$ MaxPrice $_{\text {Price }}$ PII $\left.\left._{1}\right)\right) \beta_{1}+$ & $\begin{array}{l}-0.021 \\
(-1.40)\end{array}$ & $\begin{array}{l}-0.018 \\
(-1.20)\end{array}$ & $\begin{array}{r}-0.039 \\
(-1.94)^{+}\end{array}$ & $\begin{array}{r}-0.037 \\
(-1.79)^{+}\end{array}$ & $\begin{array}{r}-0.035 \\
(-1.68)^{+}\end{array}$ & $\begin{array}{r}-0.037 \\
(-1.69)^{+}\end{array}$ \\
\hline 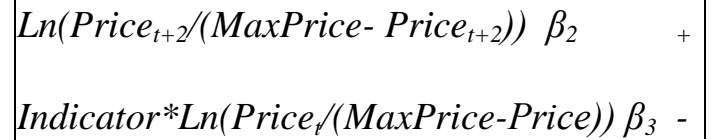 & 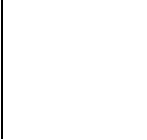 & & $\begin{array}{l}0.013 \\
(0.75)\end{array}$ & $\begin{array}{l}0.015 \\
(0.84)\end{array}$ & $\begin{array}{r}0.013 \\
(0.74) \\
-0.337\end{array}$ & $\begin{array}{r}0.010 \\
(0.55) \\
-0.362\end{array}$ \\
\hline Note: Indicator equals one if Price $_{i, t-1}<$ Price $_{i, t}$ & and zero & otherwise. & & & $(-1.87)^{+}$ & $(-1.97)^{*}$ \\
\hline $\begin{array}{l}\text { MeanScaledPrice }_{t-1} \\
\text { MeanScaledPrice }_{t} \\
\text { MeanScaledPrice }_{t+1}\end{array}$ & & & & & & $\begin{array}{r}-0.224 \\
(-0.79) \\
1.255 \\
(2.35)^{*} \\
-0.682 \\
(-1.46)\end{array}$ \\
\hline Constant & $\begin{array}{r}1.498 \\
(16.85)^{* *}\end{array}$ & $\begin{array}{r}1.511 \\
(17.14)^{* * *}\end{array}$ & $\begin{array}{r}1.699 \\
(13.32)^{* * *}\end{array}$ & $\begin{array}{r}1.675 \\
(12.52)^{* * *}\end{array}$ & $\begin{array}{r}1.639 \\
(13.02)^{* * *}\end{array}$ & $\begin{array}{r}1.186 \\
(6.67)^{* * *}\end{array}$ \\
\hline$N$ & 8,302 & 8,302 & 4,807 & 4,807 & 4,807 & 4,807 \\
\hline$R^{2}$ & 0.084 & 0.094 & 0.089 & 0.098 & 0.100 & 0.102 \\
\hline Fixed Effects for Calendar Months & No & Yes & No & Yes & Yes & Yes \\
\hline
\end{tabular}

$+\quad$ Significant at the $10 \%$ level (two tail)

* Significant at the 5\% level (two tail)

*** Significant at the $1 \%$ level (two tail)

Note: Models are estimated using Huber-White ${ }^{76}$ standard errors to allow for any lack of independence between observations for the same UPC within the sample. Use of standard errors corrected for autocorrelation using the Newey-West procedure for selected regressions does not materially change the conclusions of the paper. ${ }^{77}$

\footnotetext{
${ }^{76}$ See Huber (1967), White (1980) and Froot (1989).

${ }^{77}$ Consistent with Stock and Watson (Eqn 13.17), I use a 4 period truncation parameter when using the Newey-West procedure being estimated as $3 / 4 \mathrm{n}^{1 / 3}$ where $\mathrm{n}$ equals 104 , the number of weeks in the sample. Use of alternative truncation parameters does not change the results materially.
} 
Table 3: The Relation of Price and Just Beating Prior Year Quarterly EPS

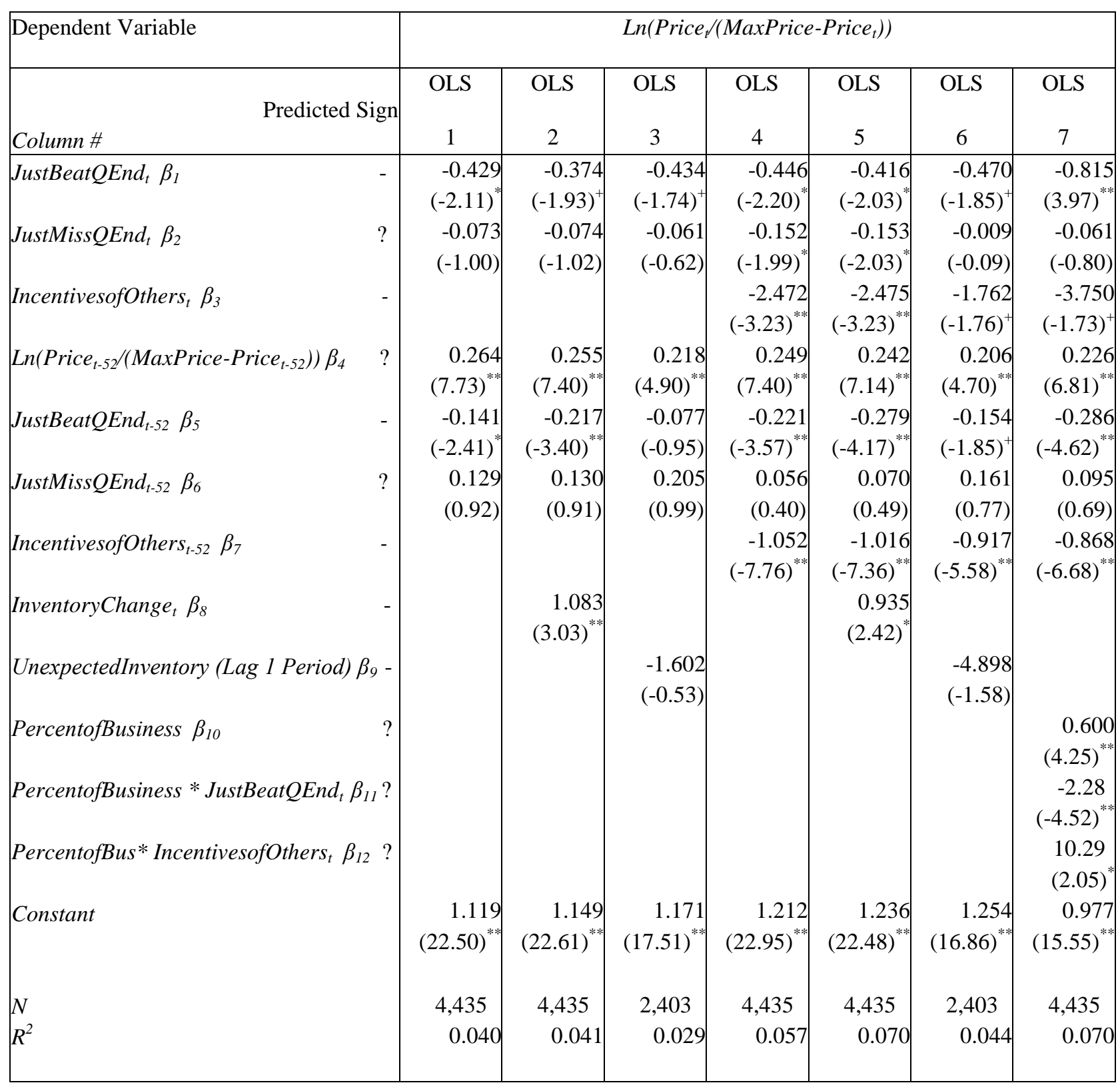

$+\quad$ Significant at the $10 \%$ level (two tail)

* Significant at the 5\% level (two tail)

** Significant at the $1 \%$ level (two tail)

Note: Models are estimated using Huber-White Standard errors to allow for any lack of independence between observations for the same UPC within the sample. Use of standard errors corrected for autocorrelation using the Newey-West procedure for selected regressions does not materially change the conclusions of the paper. 
Table 4: The Relation of Price and Just Beating Consensus Forecasts

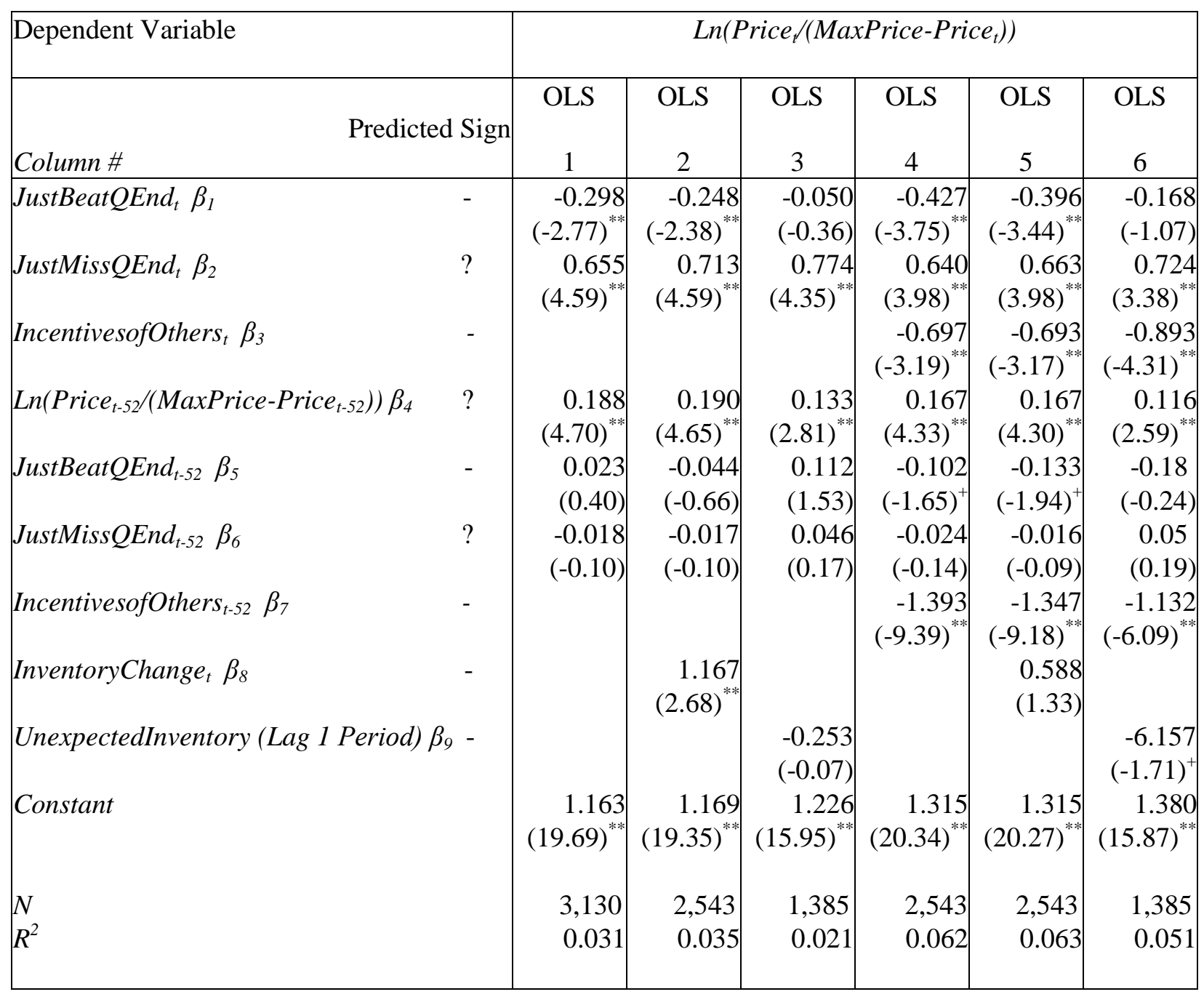

$+\quad$ Significant at the $10 \%$ level (two tail)

** Significant at the 5\% level (two tail)

** Significant at the $1 \%$ level (two tail)

Note: Models are estimated using Huber-White Standard errors to allow for any lack of independence between observations for the same UPC within the sample. Use of standard errors corrected for autocorrelation using the Newey-West procedure for selected regressions does not materially change the conclusions of the paper. 
Table 5: The Effect of Competitor Pricing on Demand Elasticity

\begin{tabular}{|c|c|}
\hline Dependent Variable & $\begin{array}{c}\text { Ln(Weekly Units } \\
\text { Sold })\end{array}$ \\
\hline & OLS \\
\hline Ln( Price $_{t-2} /\left(\right.$ MaxPrice- Price $\left.\left._{t-2}\right)\right)$ & $\begin{array}{l}0.058 \\
(2.72)^{* *}\end{array}$ \\
\hline Ln $\left(\right.$ Price $_{t-1} /\left(\right.$ MaxPrice-Price Pr- $\left.\left._{1}\right)\right)$ & $\begin{array}{c}0.062 \\
(1.89)^{+}\end{array}$ \\
\hline Ln $\left(\right.$ Price $_{t} /\left(\right.$ MaxPrice- $\left.\left._{\text {Price }}\right)\right)$ & $\begin{array}{l}-0.374 \\
(-6.22)^{* *}\end{array}$ \\
\hline Ln Price $_{t+1} /\left(\right.$ MaxPrice- Price $\left.\left._{t+1}\right)\right)$ & $\begin{array}{l}-0.059 \\
(-3.20)^{* *}\end{array}$ \\
\hline Ln$_{\left(\text {Price }_{t+2} /(\text { MaxPrice- }\right.}$ Price $\left.\left._{t+2}\right)\right)$ & $\begin{array}{c}0.013 \\
(0.69)\end{array}$ \\
\hline Indicator $*$ Ln $\left(\right.$ Price $_{t} /($ MaxPrice-Price $\left.)\right)$ & -0.303 \\
\hline Note: Indicator equals one if Price $_{i, t-1}<$ Price $_{i, t}$ and zero otherwise. & $(-1.20)$ \\
\hline MeanScaledPrice $_{t-1}$ & $\begin{array}{c}0.181 \\
(0.59)\end{array}$ \\
\hline MeanScaledPrice ${ }_{t}$ & $\begin{array}{l}1.580 \\
(2.74)^{* * *}\end{array}$ \\
\hline MeanScaledPrice ${ }_{t+1}$ & $\begin{array}{c}-1.212 \\
(-2.43)^{*}\end{array}$ \\
\hline Ln $\left(\right.$ Price $\left._{t} /(\text { MaxPrice-Price })_{t}\right) *$ End of Fiscal Quarter & $\begin{array}{c}0.018 \\
(0.36)\end{array}$ \\
\hline Ln( Price $_{t} /\left(\right.$ MaxPrice- $\left.\left._{\text {Price }}\right)\right)^{*}$ Period of High Incentive & $\begin{array}{l}-0.014 \\
(-0.18)\end{array}$ \\
\hline $\begin{array}{l}\text { Ln }\left(\text { Price }_{t} /\left(\text { MaxPrice- } \text { Price }_{t}\right)\right. \\
\text { Quarter }\end{array}$ & $\begin{array}{l}-0.121 \\
(-0.54)\end{array}$ \\
\hline MeanScaledPrice ${ }_{t}{ }^{*}$ End of Fiscal Quarter & $\begin{array}{l}-0.210 \\
(-1.26)\end{array}$ \\
\hline MeanScaledPrice ${ }_{t}{ }^{*}$ Period of High Incentive & $\begin{array}{l}-0.600 \\
(-1.25)\end{array}$ \\
\hline MeanScaledPrice ${ }_{t}^{*}$ Period of High Incentive * End of Fiscal Quarter & $\begin{array}{c}0.261 \\
(0.74)\end{array}$ \\
\hline End of Fiscal Quarter & $\begin{array}{c}0.204 \\
(0.98)\end{array}$ \\
\hline Period of High Incentive & $\begin{array}{l}0.536 \\
(0.92)\end{array}$ \\
\hline Constant & $\begin{array}{l}1.025 \\
(4.65)^{* *}\end{array}$ \\
\hline $\begin{array}{l}N \\
R^{2}\end{array}$ & $\begin{array}{l}4,643 \\
0.118\end{array}$ \\
\hline Fixed Effects for Calendar Months & Yes \\
\hline
\end{tabular}

